\title{
Review of hypersonic research investigations in IISc shock tunnel (HST1)
}

\author{
N M REDDY, K NAGASHETTY, G JAGADEESH and K P J REDDY \\ Department of Aerospace Engineering, Indian Institute of Science, \\ Bangalore 560 012, India \\ email: laser@aero.iisc.ernet.in \\ MS received 11 April 1996; revised 16 August 1996
}

\begin{abstract}
Real gas effects dominate the hypersonic flow fields encountered by modern day hypersonic space vehicles. Measurement of aerodynamic data for the design applications of such aerospace vehicles calls for special kinds of wind tunnels capable of faithfully simulating real gas effects. A shock tunnel is an established facility commonly used along with special instrumentation for acquiring the data for this purpose within a short time period. The hypersonic shock tunnel (HST1), established at the Indian Institute of Science (IISc) in the early 1970s, has been extensively used to measure the aerodynamic data of various bodies of interest at hypersonic Mach numbers in the range 4 to 13. Details of some important measurements made during the period 19751995 along with the performance capabilities of the HST1 are presented in this review. In view of the re-emergence of interest in hypersonics across the globe in recent times, the present review highlights the suitability of the hypersonic shock tunnel at the IISc for future space application studies in India.
\end{abstract}

Keywords. Shock tunnel; shock waves; boundary layers; real gas effects; heat transfer; hypersonic aerodynamics.

\section{Introduction}

There has been renewed interest in the field of hypersonics in recent times due to the proposed plans for the development of reusable space planes and aero-assisted space transfer vehicles. The major activity in this direction includes the American NASP, the British HOTOL, the Japanese HOPE and Indian Aerospace plane. This resurgence in hypersonics has spurred active research in many aspects of hypersonic flight encountered by these vehicles. Research in this area can broadly be categorized into computational fluid dynamics (CFD) studies and experimental research in ground-based facilities such as hypersonic wind/shock tunnels capable of simulating the flight conditions in the laboratory. 
Experimental flow field and surface measurements often supply data for the validation of the CFD codes and also help in understanding the hypersonic flow phenomena.

A distinct feature of flight at hypersonic Mach numbers is the occurrence of real gas effects due to the passage of air through the bow shock wave in front of the vehicle which results in the sudden increase of temperature and pressure. The temperature rise is proportional to the square of the speed, for sufficiently high-speed flights. On some parts of the vehicle, such as nose or leading edge, the temperature rise may be high enough even to dissociate and ionize air molecules. This results in the altering of the flow characteristics over the vehicle and constitutes the real gas effects which are very difficult to analyse theoretically. Thus, these effects are often estimated experimentally by simulating the hypersonic flow over scaled-down models of the prototypes.

In a blowdown type hypersonic wind tunnel, the required flow Mach number in the test section is achieved by decreasing the freestream temperature which results in reducing the speed of sound leading to corresponding increase in the Mach number. The upper limit on the Mach number is imposed for a given reservoir temperature by condensation of the test gas in the test section. Thus conventional blowdown type hypersonic wind tunnels are capable of producing high flow Mach numbers but without the accompanying high temperatures to simulate real gas effects. This regime is usually referred to as MachReynolds-simulation (Hornung 1988) in which air may still be considered as a perfect gas. However, this does not provide correct simulation above Mach number 6 , since the occurrence of real gas effects is coupled to the temperature. Real gas effects can be effectively simulated by generating air flow in the tunnel with energy matching that in flight of the hypersonic vehicle, and can be achieved by expanding the test gas from a reservoir at very high temperature and pressure through a nozzle. This is achieved in a shock tunnel by using a shock wave to heat and compress the test gas rapidly and expanding the shocked gas through a nozzle to the required Mach number in the test section.

A hypersonic shock tunnel, HST1, established at the Indian Institute of Science (IISc) has been in operation for the past two decades with upgradation of the data acquisition system from time to time. The tunnel has been extensively used for measurements such as aerodynamic forces and heat transfer rates over bodies of interest at Mach numbers varying from 4 to 13 . The purpose of the present paper is to review the important contributions made by using the HST1 tunnel along with the description of the instrumentation developed specific to measurements in short duration test facilities. A brief description of the performance capabilities of the shock tunnel is presented before describing the important results obtained. In addition a brief description of the proposed improvements for enhancing the performance capabilities of the shock tunnel along with the proposed new techniques for the flow visualization at hypersonic Mach numbers in the tunnel are presented.

\section{Description of the IISc hypersonic shock tunnel}

The hypersonic shock tunnel (Reddy 1978) consists of a shock tube and the wind tunnel sections, as shown in figure 1a. The corresponding $x$ - $t$ diagram is shown in figure $1 \mathrm{~b}$ and describes the principle of operation. The shock tube is an aluminium tube of $101 \mathrm{~mm}$ 


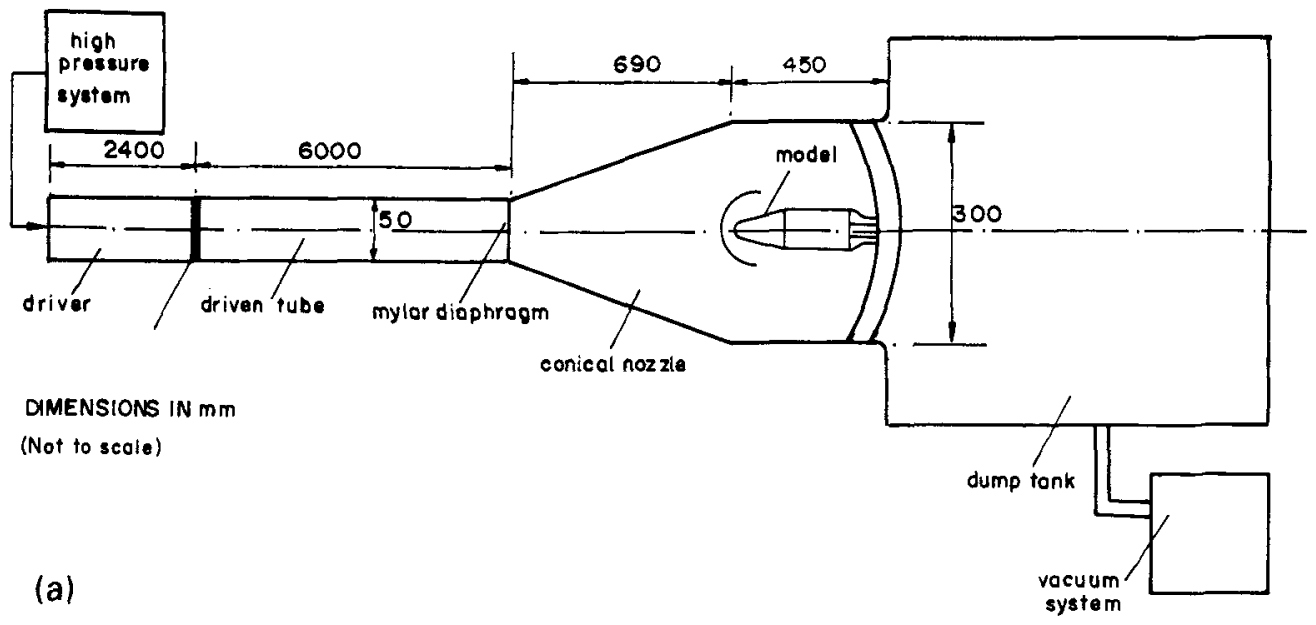

(b)

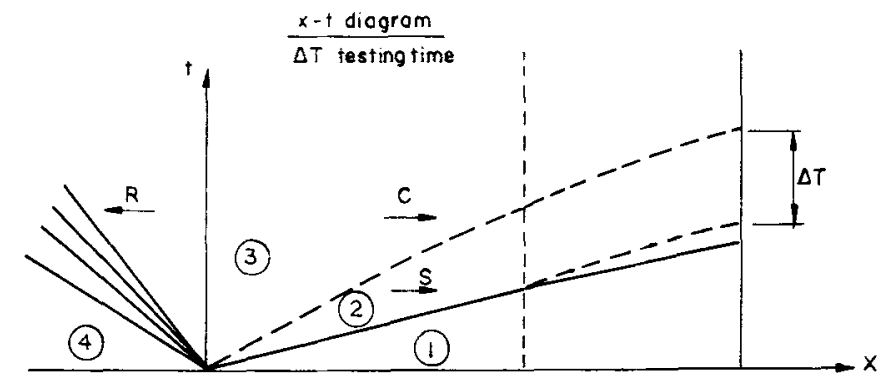

Figure 1. Schematic diagram of a typical shock tunnel (a), along with an $x$ - $t$ diagram (b)

outer diameter and $50.7 \mathrm{~mm}$ inner diameter separated into driver and driven sections by an aluminium diaphragm of $3 \mathrm{~mm}$ thickness. The $2.4 \mathrm{~m}$ long driver is equipped with an arrangement to feed high pressure driver gas from the high pressure cylinders. The $6.0 \mathrm{~m}$ long driven section has provision for evacuating the tube, feeding any desired test gas and measuring the vacuum level. In addition, two ports $30.5 \mathrm{cms}$ apart are located towards the end of the driven section for the purpose of shock speed measurement. The pressure behind the primary and the reflected shock waves is monitored by a pressure transducer at the end of the driven section.

The wind tunnel section separated from the shock tube by a thin paper diaphragm consists of a nozzle attached to the end of the shock tube which terminates in a $45 \mathrm{~cm}$ long test section of $30 \mathrm{~cm} \times 30 \mathrm{~cm}$ size. The test section is provided with circular optical quality glass windows for visual observations. A large tank of $0.72 \mathrm{~m}^{3}$ volume is attached to the end of the test section to collect the test gas in every run and also to swallow all the shock and compression waves that are created during the starting process in the nozzle. The tunnel section, downstream of the paper diaphragm, is evacuated to a vacuum level of the order of $10^{-6} \mathrm{mbar}\left(1 \mathrm{mbar}=10^{2} \mathrm{~Pa}\right)$ using a rotary pump-diffusion pump combination supplied by the Hind High Vacuum Co. Ltd., Bangalore.

The nozzle at the end of the shock tube expands the test gas at high temperature and pressure behind the shock wave to any required Mach number in the test section, if the appropriate area ratio is maintained. The tunnel when operated in straight-through mode 


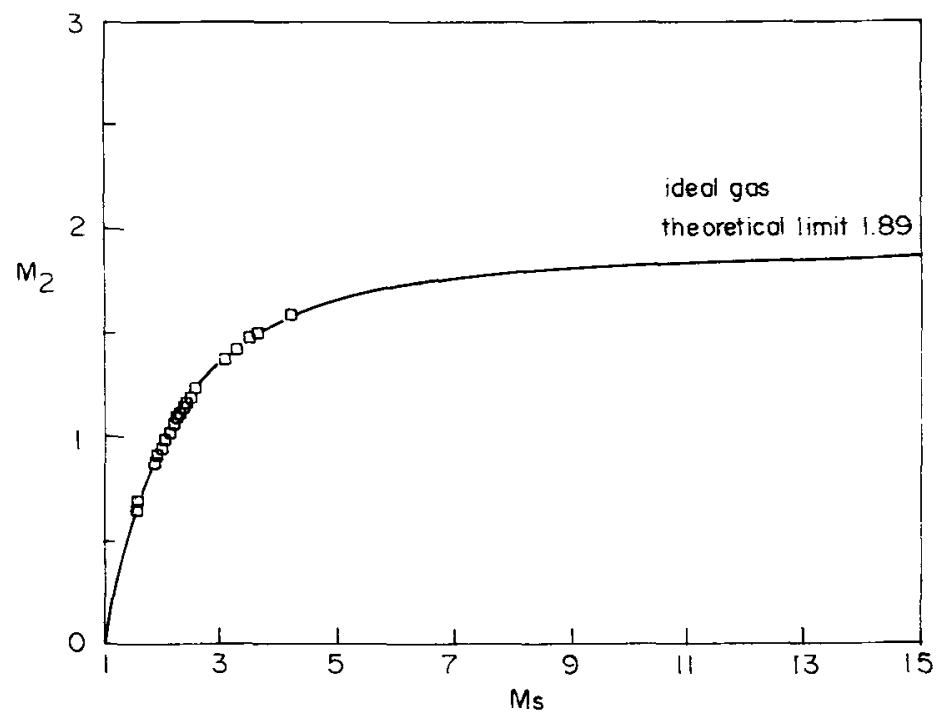

Figure 2. Variation of the flow Mach number $\mathrm{M}_{2}$ behind the shock wave with the shock strength in the shock tube. The shock Mach number range is varied by using air, helium and hydrogen as driver gases.

uses truncated conical nozzles with an entrance diameter of $50.7 \mathrm{~mm}$ and exit diameters of $300 \mathrm{~mm}$ and $150 \mathrm{~mm}$ to yield flow Mach numbers of 6 and 4, respectively. The tunnel is operated in the reflected mode by adding a short section of convergent-divergent nozzle with throat diameter varying from $25 \mathrm{~mm}$ to $7 \mathrm{~mm}$, which yields flow Mach numbers varying from 7 to 13 respectively. However, no efforts were made to operate the tunnel in a tailored mode to enhance the test time. Further details of the hypersonic shock tunnel have been reported earlier (Reddy 1978).

Thin film heat transfer gauges located $30.5 \mathrm{~cm}$ apart at the end of the driven section sense the arrival of the shock front due to the sudden jump in the surface temperature of thin films. An electronic counter is triggered on by the signal from the first gauge and switched off by the signal from the second gauge. Thus the counter reading in microseconds indicates the transit time of the shock wave. The pressure jump across the shock wave is monitored by a piezoelectric pressure transducer ( $\mathrm{PCB}$ piezotronics) mounted flush with the inner surface of the tube at the end of the driven section. The performance of the shock tube is indicated by the calibration curve shown in figure 2 .

\section{Measurement of aerodynamic forces over missile shaped bodies}

Since the duration of the uniform flow in the shock tunnel is only a few milliseconds, regular force balances used in conventional blowdown type wind tunnels cannot be used to obtain aerodynamic data. Hence special techniques, like monitoring of the motion of the free-flying model during the run using a high speed photographic technique and an interferometric technique with a reflectometer mounted on the model, have been tried out to measure the aerodynamic force data (Bernstein and Stott 1981). However these techniques have inherent drawbacks of integrity of the model and complexity of model making. 


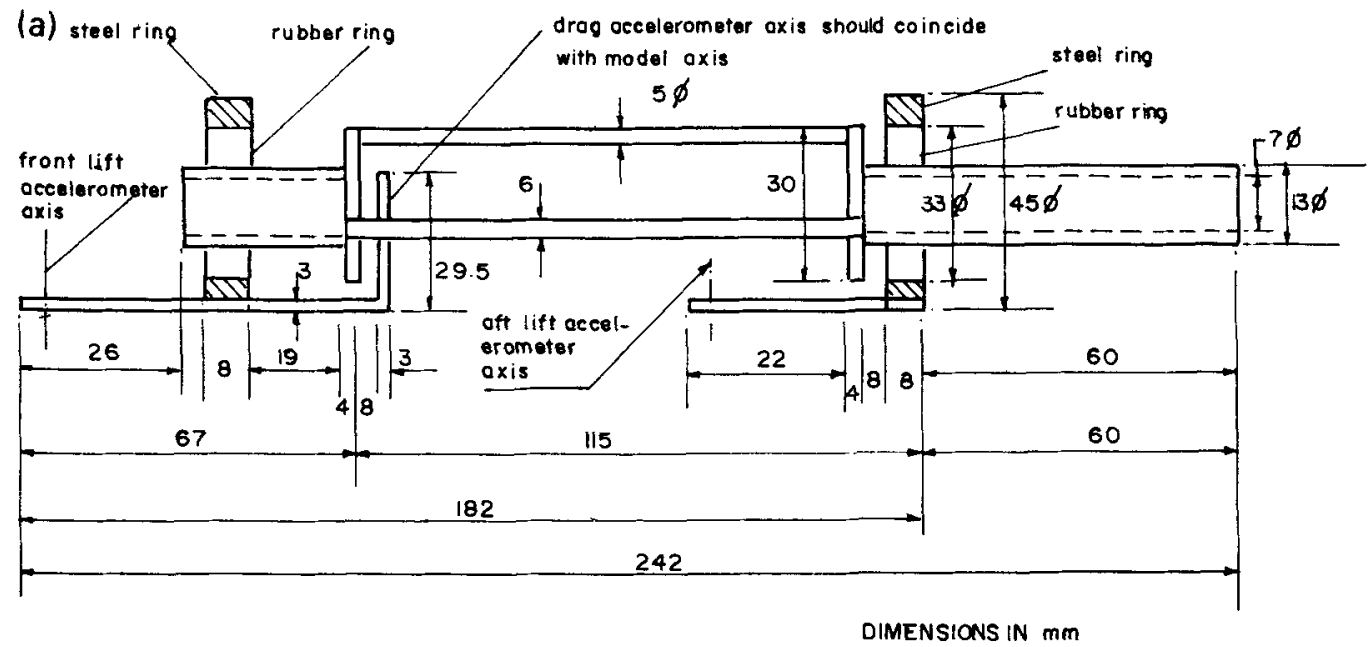

(b)

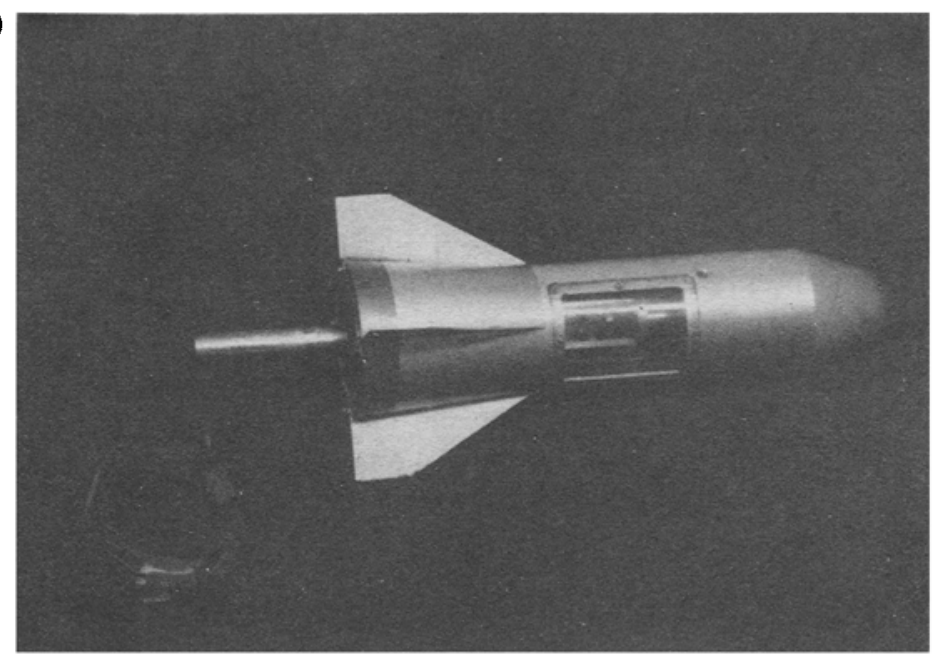

Figure 3. (a) Assembly diagram of the three component fast response force balance system and (b) a photograph of the complete balance system along with one of the test models.

A novel three-component balance system using fast response accelerometers with a response time of fraction of a millisecond has been developed for the first time for use in the HST1. A schematic diagram of the balance system is shown in figure $3 a$ and a photograph of the balance system along with a typical missile model is shown in figure $3 \mathrm{~b}$. The details of this balance system along with the basic theory have been reported earlier (Reddy 1983: Joshi \& Reddy 1986: Channa Raju \& Reddy 1990).

This balance system has been successfully used to measure the aerodynamic force coefficients like the lift, drag and moment over different aerodynamic bodies of interest flying at Mach numbers 3.85, 5.5 and 9.15 (Shah 1983: Joshi 1985: Joshi \& Reddy 1985 , 1986; Channa Raju 1989; Channa Raju \& Reddy 1990). Model configurations chosen for the investigations are the typical nose cone-cylinder configurations used for missiles and re-entry vehicles. The list of models along with the Mach numbers is presented in 
Table 1. Details of the models used for aerodynamic force measurements in HST1.

\begin{tabular}{lll}
\hline Model $^{*}$ & Flare angle & Mach number \\
\hline Blunt nose cone-cylinder & No flares & $3.85 ; 5.5$ \\
Blunt nose cone-cylinder with flares \& fins & $10^{\circ}$ & $3.85 ; 5.5 ; 9.15$ \\
Blunt nose cone-cylinder with flare \& fins & $5^{\circ}$ & $3.85 ; 5.5 ; 9.15$ \\
Sharp nose cone-cylinder & No flare & 5.5 \\
\hline
\end{tabular}

${ }^{*}$ Blunt nose radius $=0.015 \mathrm{~m}$; half angle $=10.5^{\circ} ;$ length $=0.2266 \mathrm{~m}$.

table 1. The flowfields around these models at hypersonic Mach numbers described by full Navier-Stokes equations are extremely complex to investigate analytically. Hence the experimental data presented here are of great importance in understanding the aerodynamic behaviour of these bodies at high Mach numbers.

The measured force coefficients based on the body diameters are shown in figures 4 to 6 for all models at angles of attack varying from $0^{\circ}$ to $17^{\circ}$. The experimental results are compared with the theoretical force coefficients predicted using modified Newtonian theory which takes into account the centrifugal forces over the spherical portion of the models (Truitt 1959). The measured data match very well with predicted values for the lift coefficient. Other important conclusions drawn from these studies are that for the sharp nose cone-cylinder and blunt nose cone-cylinder models the flow separation may be occurring at about $12^{\circ}$ angle of attack. Flow separation is delayed by the addition of flare and fins. The measured values of drag coefficient at all Mach numbers are found to be higher than predicted values. This may be due to the fact that the Newtonian theory does not include the contribution of the skin friction to the total drag. The lift coefficient decreases with the increase of the flow Mach number for all the models, whereas the dependence of the drag coefficient on the Mach number is negligible. The measured values of moment coefficients for all the models at all three test Mach numbers match predicted values very well.

\section{Heat transfer rate measurements}

A small fraction of the kinetic energy of a flight vehicle is converted into heat energy and transferred to the body from the fluid medium surrounding the vehicle by convection. At hypersonic speeds, this small fraction can result in an enormous amount of heat energy and hence aerodynamic heating becomes a major design concern. For designing the thermal protection system of the flight vehicle, one needs to know the convective heat transfer rates to the body as accurately as possible. Heat transfer data that can be properly correlated to the flight are measured in the shock tunnel by simulating the Mach number, Reynolds number and the total temperature of the flight.

The HST1 tunnel has been used extensively to measure the heat transfer data on different bodies of interest at various Mach numbers and over a spectrum of Reynolds numbers. Details of these measurements along with the model details and important results are summarized in the following sections. 

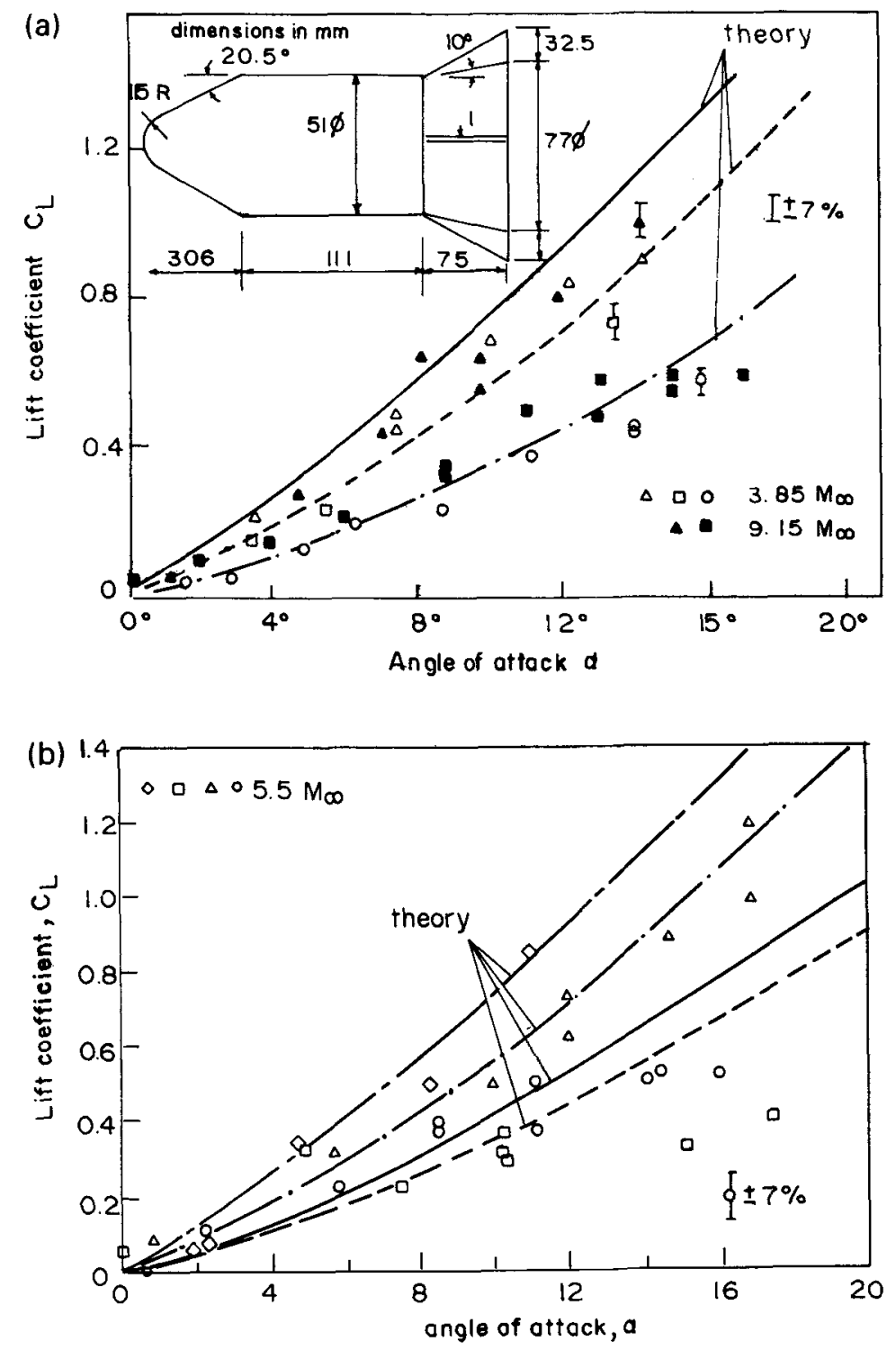

Figure 4. Variation of the experimental and theoretical values of the lift coefficient with angle of attack at different flow Mach numbers. (a) $\Delta$, - blunt nose cone cylinder with $10^{\circ}$ flare-fins; $\square,--$ blunt nose cone cylinder with $5^{\circ}$ flare-fins; 0 , - - blunt nose cone cylinder. (b) 0 , - sharp nose cone cylinder; $\square,--$ blunt nose cone cylinder; $\Delta-\cdot-$ blunt nose cone cylinder with $5^{\circ}$ flare-fins; $\diamond,--\ldots$ blunt nose cone cylinder with $10^{\circ}$ flare-fins. 

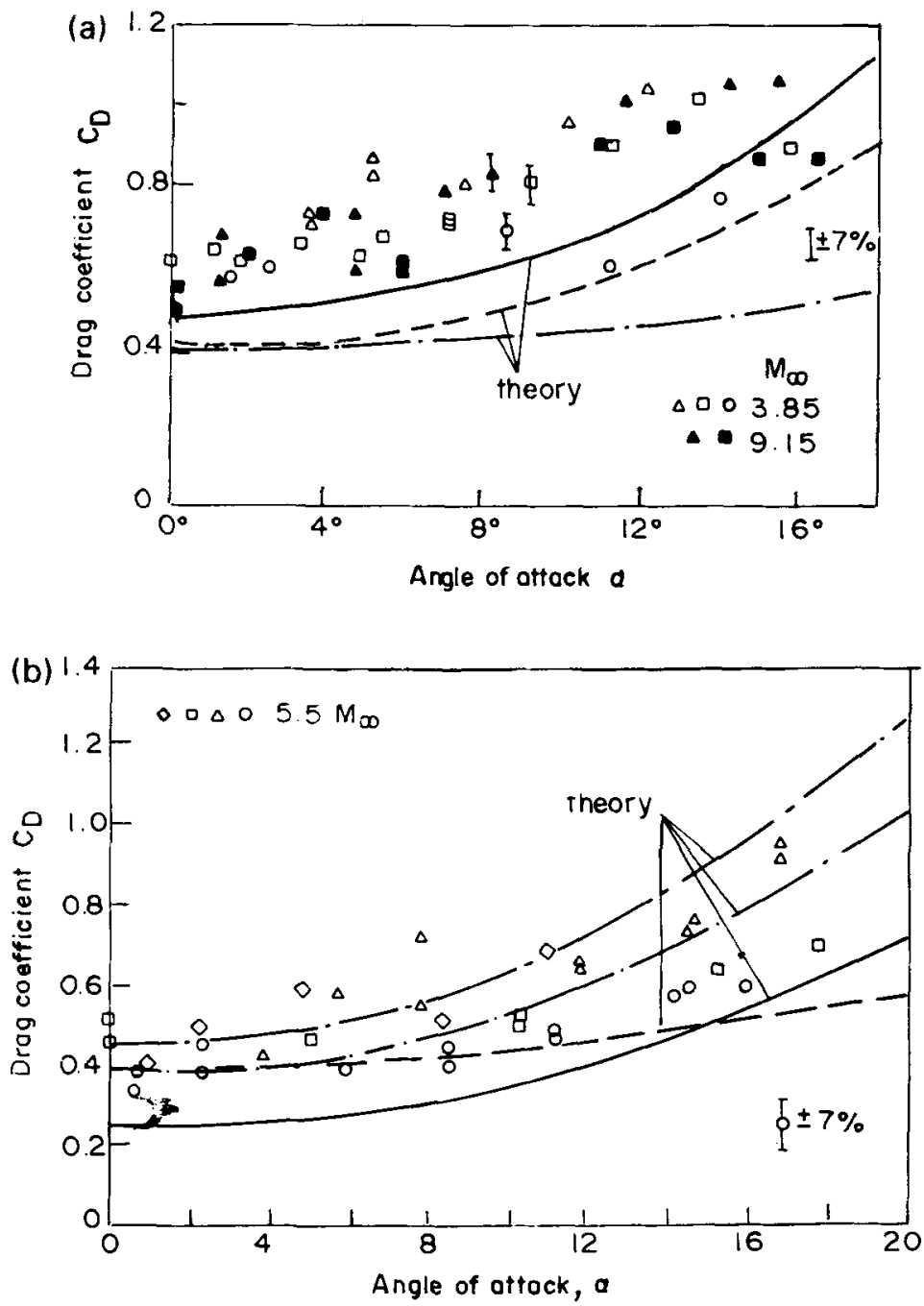

Figure 5. Variation of the experimental and theoretical values of the drag coefficient with angle of attack for different flow Mach numbers; (a) and (b) as in figure 4.

\subsection{Heat transfer over a flat plate}

A flat plate model of $22.9 \mathrm{~cm}$ length and $20 \mathrm{~cm}$ width, with a sharp leading edge as shown in figure 7, and made of an aluminium alloy has been used for heat transfer data measurements. The nose angle of $35^{\circ}$ is chosen so as to ensure an attached shock wave at the bottom of the plate. The thickness of the model is fixed such that it can accommodate the heat transfer gauges mounted flush with the flat plate surface. These gauges are mounted along the centreline at locations indicated in the figure.

Platinum thin film gauges on the surface of the flat plate are used as fast response thermometers to sense the surface temperature history during the hypersonic flow over the model. The thin film of platinum is obtained by firing platinum paint on an insulating surface such as a Pyrex rod of $9 \mathrm{~mm}$ length and $10 \mathrm{~mm}$ diameter (Baskaran 1977; Remesh 1996). 

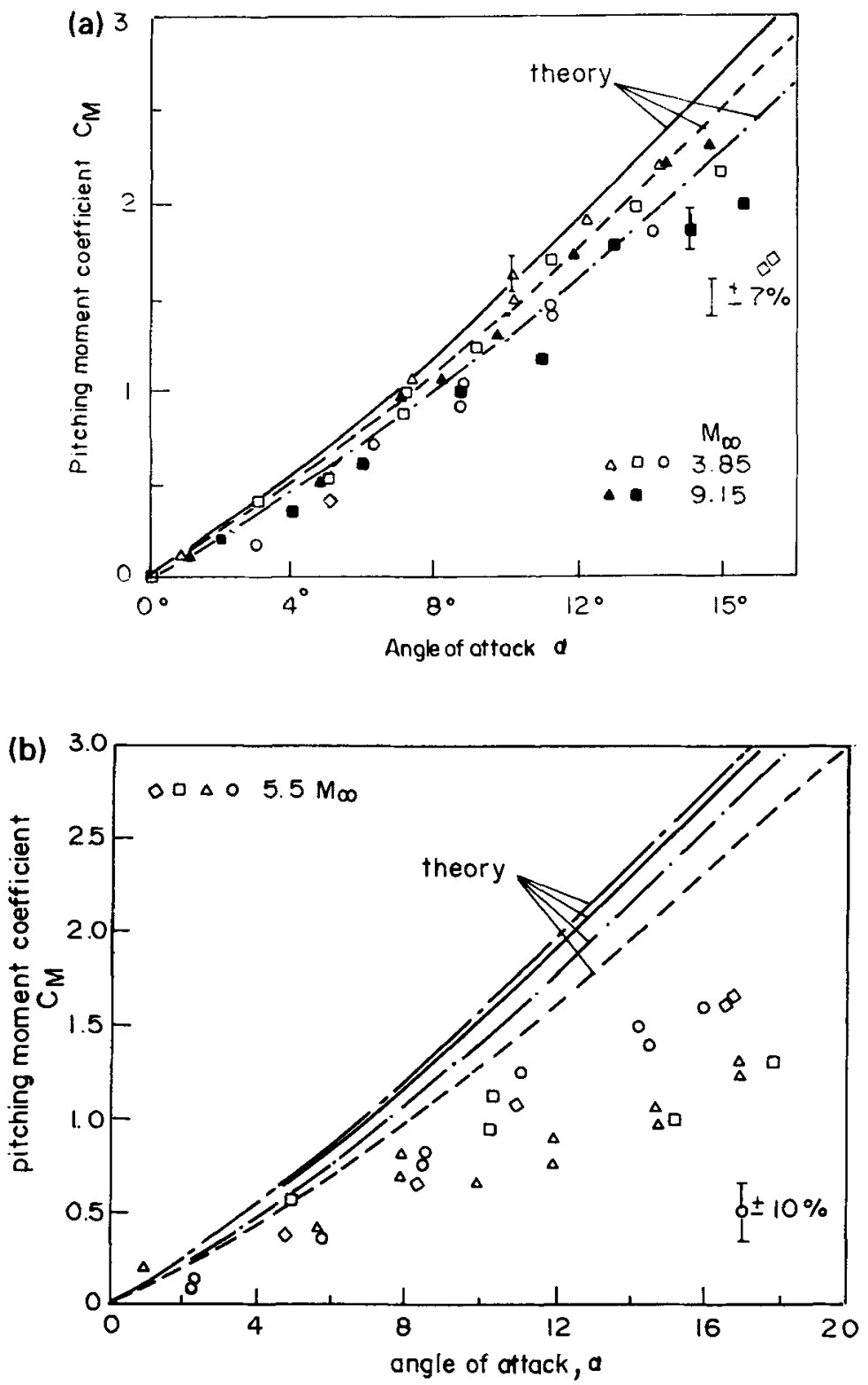

Figure 6. Variation of the experimental and theoretical values of the pitching moment coefficient with the angle of attack for different flow Mach numbers: (a) and (b) as in figure 4. 
Table 2. List of components used in the circuit diagram given in figure $8 . \mathrm{R}=$ resistor; $\mathrm{P}=$ potentiometer; $\mathrm{D}=$ diode; $\mathrm{T}=$ transistor; $\mathrm{C}=$ capacitor.

\begin{tabular}{llll}
\hline Component & Specifications & Component & Specifications \\
\hline R1 & $4.7 \mathrm{k} \Omega, 1 / 4 \mathrm{~W}$ & $\mathrm{P} 1$ & $1 \mathrm{k} \Omega, 10$ turn \\
R2 & $100 \Omega, 1 / 2 \mathrm{~W}$ & $\mathrm{P} 2$ & $100 \mathrm{k} \Omega, 10$ turn \\
R3 & $10 \mathrm{k} \Omega, 1 / 4 \mathrm{~W}$ & $\mathrm{P} 1$ & $250 \Omega, 10$ turn \\
R5 & $3.3 \mathrm{k} \Omega, 1 / 4 \mathrm{~W}$ & $\mathrm{D} 1$ & $5.6 \mathrm{Vz}$ \\
R6 & $120 \mathrm{k} \Omega, 1 / 4 \mathrm{~W}$ & $\mathrm{D} 2$ & $1 \mathrm{~N} 4002$ \\
R7 & $1.8 \mathrm{k} \Omega, 1 / 4 \mathrm{~W}$ & $\mathrm{~T} 1$ & $\mathrm{SL} 100$ \\
R10 to R19 & $10 \mathrm{k} \Omega, 1 / 4 \mathrm{~W}, \pm 1 \%$ & $\mathrm{~T} 2$ & $\mathrm{BC} 109$ \\
R20 to R39 & $10 \mathrm{k} \Omega, 1 / 4 \mathrm{~W}, \pm 5 \%$ & $\mathrm{IC} 1$ & $\mathrm{LM} 318$ \\
R40 & $5 \mathrm{k} \Omega, 1 / 4 \mathrm{~W}, \pm 1 \%$ & $\mathrm{IC} 2$ & $\mu \mathrm{A} 741$ \\
R41 & $2.7 \mathrm{k} \Omega, 1 / 4 \mathrm{~W}$ & $\mathrm{IC} 3$ & $\mathrm{LM} 324$ \\
R42 & $100 \Omega, 1 / 4 \mathrm{~W}$ & $\mathrm{IC} 4$ & $\mathrm{SN} 74121$ \\
R43 \& R44 & $1 \mathrm{k} \Omega, 1 / 4 \mathrm{~W}$ & $\mathrm{C} 1$ & $100 \mu \mathrm{F}, 25 \mathrm{~V}$ \\
R45 & $100 \mathrm{k} \Omega, 1 / 4 \mathrm{~W}$ & $\mathrm{C} 2$ & $0.1 \mu \mathrm{F}, 30 \mathrm{~V}$ \\
R46 & $10 \mathrm{k} \Omega, 1 / 4 \mathrm{~W}$ & $\mathrm{C} 3$ & $1 \mu \mathrm{F}, 20 \mathrm{~V}$ \\
R47 & $100 \mathrm{k} \Omega, 1 / 4 \mathrm{~W}$ & $\mathrm{C} 4$ & $0.1 \mu \mathrm{F}, 30 \mathrm{~V}$ \\
R48 to R50 & $1 \mathrm{k} \Omega, 1 / 4 \mathrm{~W}$ & $\mathrm{C} 5$ & $0.1 \mu \mathrm{F}, 30 \mathrm{~V}$ \\
R51 & $100 \mathrm{k} \Omega, 1 / 4 \mathrm{~W}$ & $\mathrm{C} 7$ & $0.1 \mu \mathrm{F}, 25 \mathrm{~V}$ \\
R52 & $10 \mathrm{k} \Omega, 1 / 4 \mathrm{~W}$ & $\mathrm{C} 8$ & $0.1 \mu \mathrm{F}, 30 \mathrm{~V}$ \\
R53 & $100 \mathrm{k} \Omega, 1 / 4 \mathrm{~W}$ & $\mathrm{C} 9, \mathrm{C} 42, \mathrm{C} 44$ & \\
R54 & $330 \Omega, 1 / 4 \mathrm{~W}$ & $\mathrm{C} 47, \mathrm{C} 49$ & $100 \mu \mathrm{F}, 25 \mathrm{~V}$ \\
R55 & $220 \Omega, 1 / 4 \mathrm{~W}$ & & \\
R56 & $10 \mathrm{k} \Omega, 1 / 4 \mathrm{~W}$ & $\mathrm{C} 10$ & $0.1 \mu \mathrm{F}, 30 \mathrm{~V}$ \\
C11 to C40 & $2200 \mathrm{pF}, \pm 5 \%, 60 \mathrm{~V}$ & $\mathrm{C} 41, \mathrm{C} 43, \mathrm{C} 45$ & \\
C51 & $0.01 \mu \mathrm{F}, 30 \mathrm{~V}$ & $\mathrm{C} 46, \mathrm{C} 48 \& \mathrm{C} 50$ & \\
\hline
\end{tabular}

The film is energised with a constant $20 \mathrm{~mA}$ current. The rise in the surface temperature during the flow causes a change in the resistance of the film which induces a corresponding voltage jump across the gauge. Thus the variation of the film resistance with time represents the time history of the surface temperature during the flow. This surface temperature history can be directly converted to heat transfer rate by an analogue electrical RC network, built using the analogy between the heat conduction into the body and current conduction. The circuit consisting of a large number of RC combinations having a time constant of 22 microseconds is shown in figure 8 and the values of the components used in this circuit are given in table 2 . The complete instrumental set-up for heat transfer rate measurements in the shock tunnel is shown in figure 9. Data from the heat transfer gauges are acquired and processed using a multichannel transient recorder (Data Lab, UK) with a sampling rate of 2 million samples per second. Details of the data acquisition system coupled to a computer for processing the data have been reported earlier (Reddy \& Reddy 1988). 


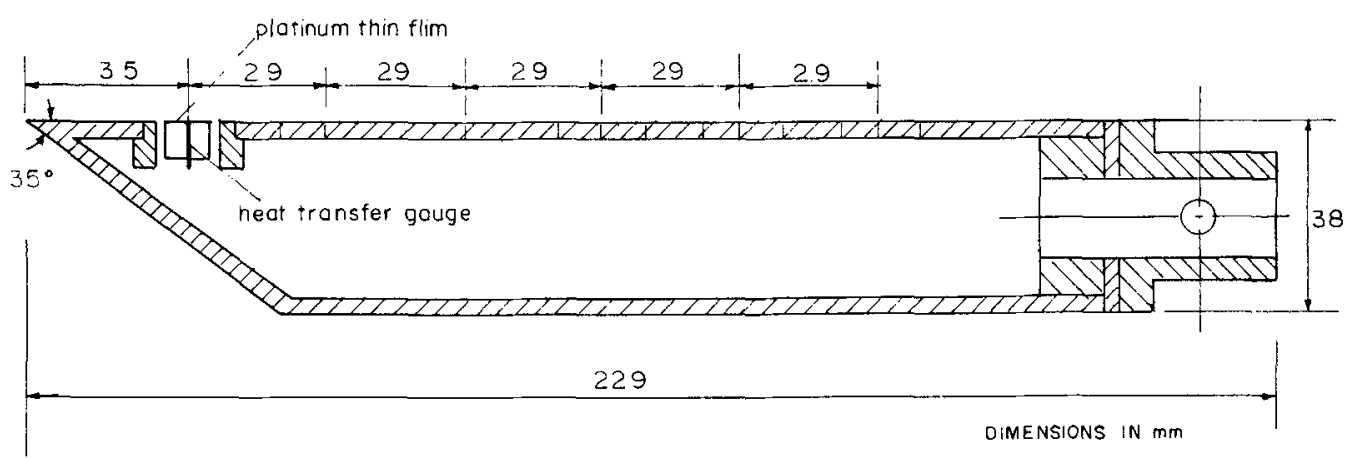

Figure 7. Schematic diagram of a flat plate model.

Results of the experimentally measured heat transfer data in HST1 for the flat plate are presented in figures 10 to 14 . All the data are measured at zero angle of attack for flow Mach number 5.75, with Reynolds number varying in the range $2 \times 10^{4}$ to $2.5 \times 10^{5}$. The higher values of Reynolds number were obtained by using helium as the driver gas while the lower values were obtained using nitrogen as the driver gas in the shock tunnel. Heat transfer data in terms of the Stanton number are presented in figure 10 as a function of local Reynolds number along the plate surface. These data have been used to estimate the skin friction coefficient using Reynold's analogy between skin friction and heat transfer coefficient (Anderson 1989; Remesh 1996). The variation of skin friction along the flat plate surface is shown in figure 11 as a function of local Reynolds number. The Stanton number and the skin friction coefficients at different locations along the centre line of the plate are shown in figures 12 and 13 . Viscous effects within the boundary layer lead to increase in temperature and reduction in gas density which ultimately enhance the thickness of the boundary-layer downstream of the leading edge of the flat plate. This growing viscous boundary-layer thickness in turn induces viscous interaction which affects the surface pressure distribution, lift, drag and stability of hypersonic vehicles. The similarity parameter governing the viscous interaction, $\bar{\chi}=\mathrm{M}_{\infty}^{3} \sqrt{C} / \sqrt{\mathrm{Re}}$, where $C=\rho_{w} \mu_{w} / \rho_{e} \mu_{e}, \mathbf{M}_{\infty}$ is the freestream Mach number, Re is the Reynolds number, $\rho$ is the density and $\mu$ is the viscosity coefficient, can be used to ascertain the viscous interaction effects. In the present study the value of the viscous parameter was in the range 0.3 to 1.5 , indicating that the viscous interaction is very weak. The dependence of the heat transfer coefficient on the viscous interaction parameter is shown in figure 14. The theoretical data computed using full Navier-Stokes equations in the conservative form are also plotted in figures 10 to 14, along with the experimental data. These equations are solved using a 2-D laminar flow code developed recently based on the finite volume method (Sreekanth 1993).

The above results show that the measured heat transfer data match the theoretical values very well. Since the local Reynolds number is well below the critical Reynolds number for the transition from laminar to turbulent boundary layer, the flow over the entire flat plate is laminar. Therefore, the heat transfer coefficient decreases along the length of the plate. Since the interaction parameter is found to be very low, the viscous interaction effect is very weak and its effect on the heat transfer coefficient along the length of the plate is negligible. 


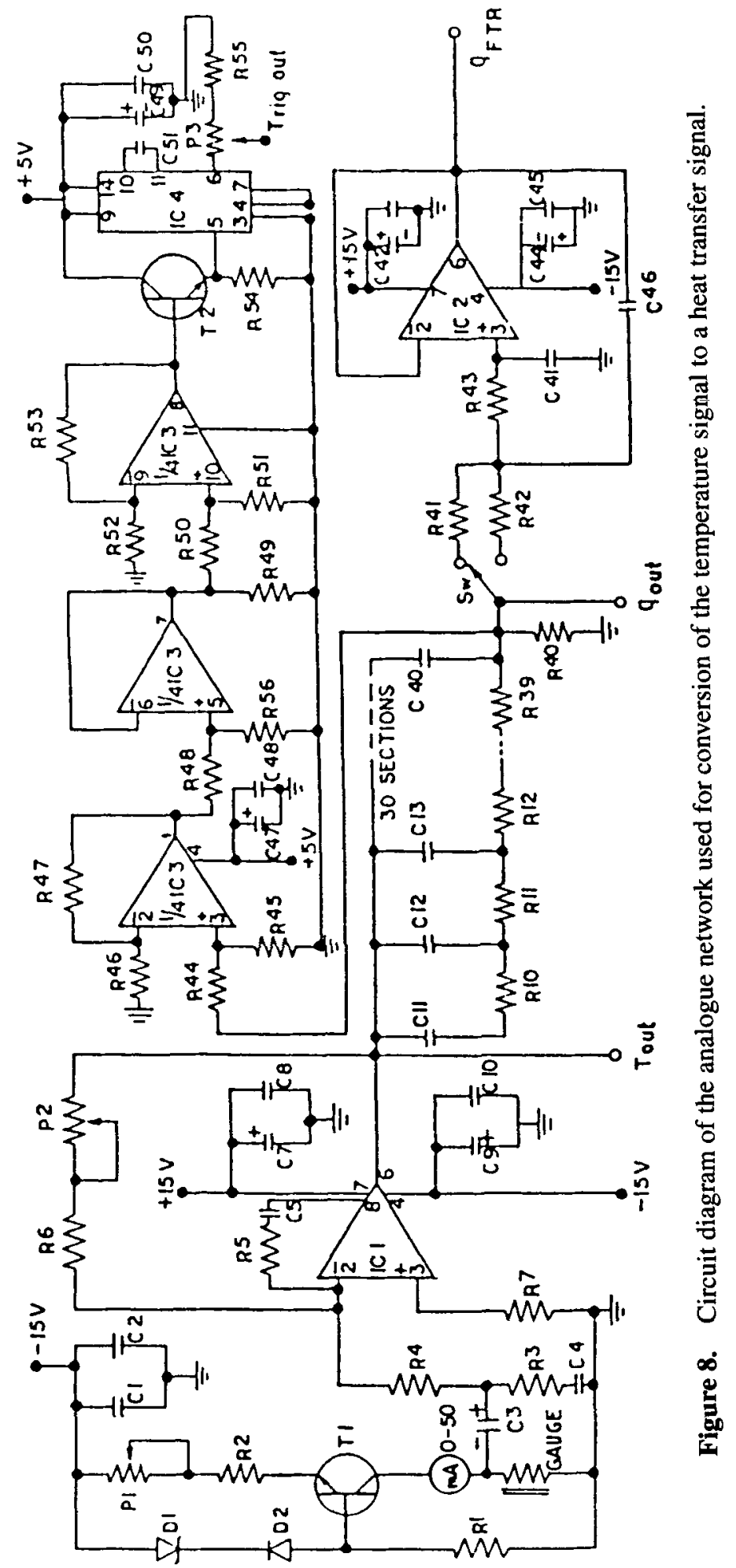




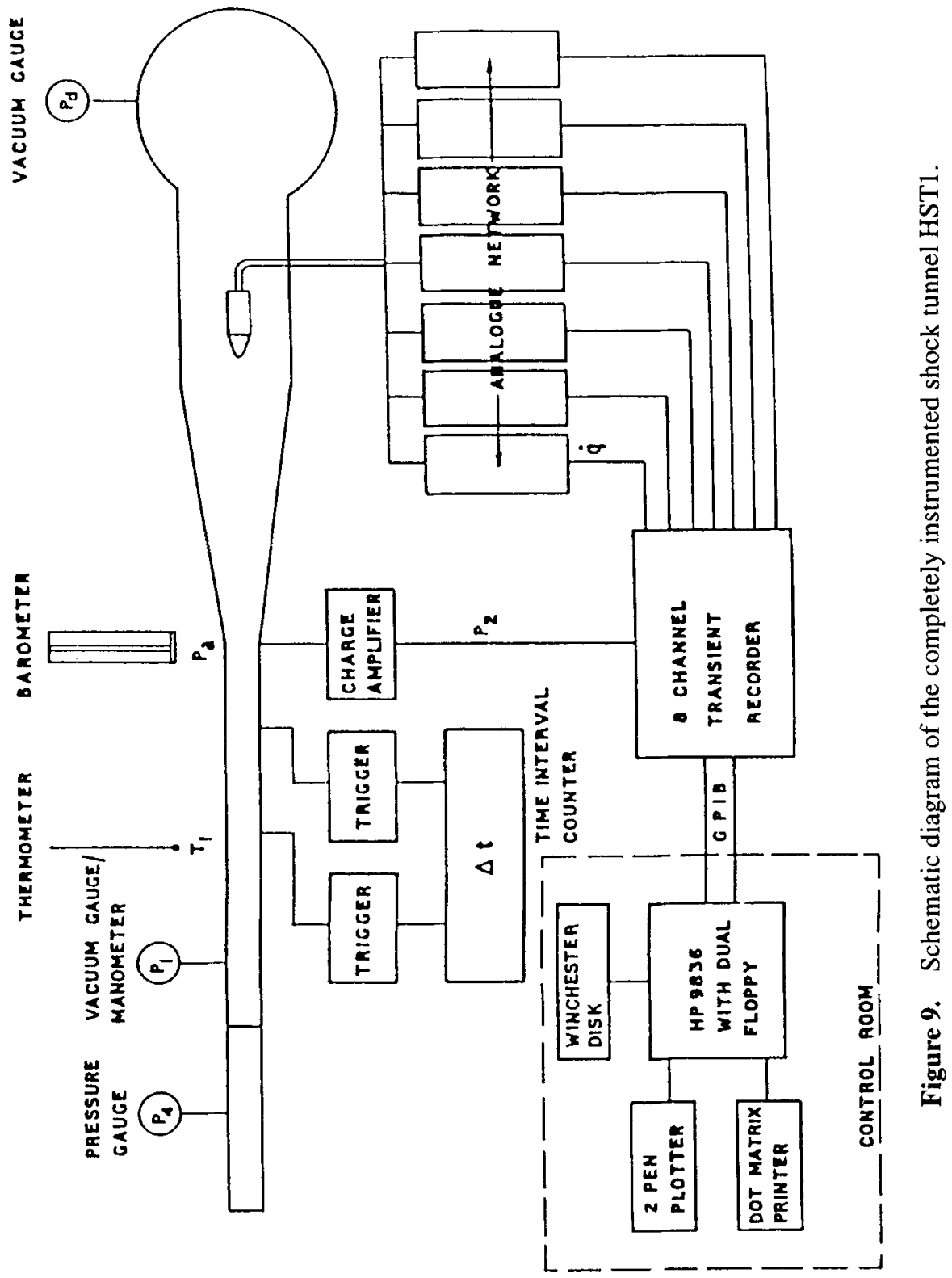




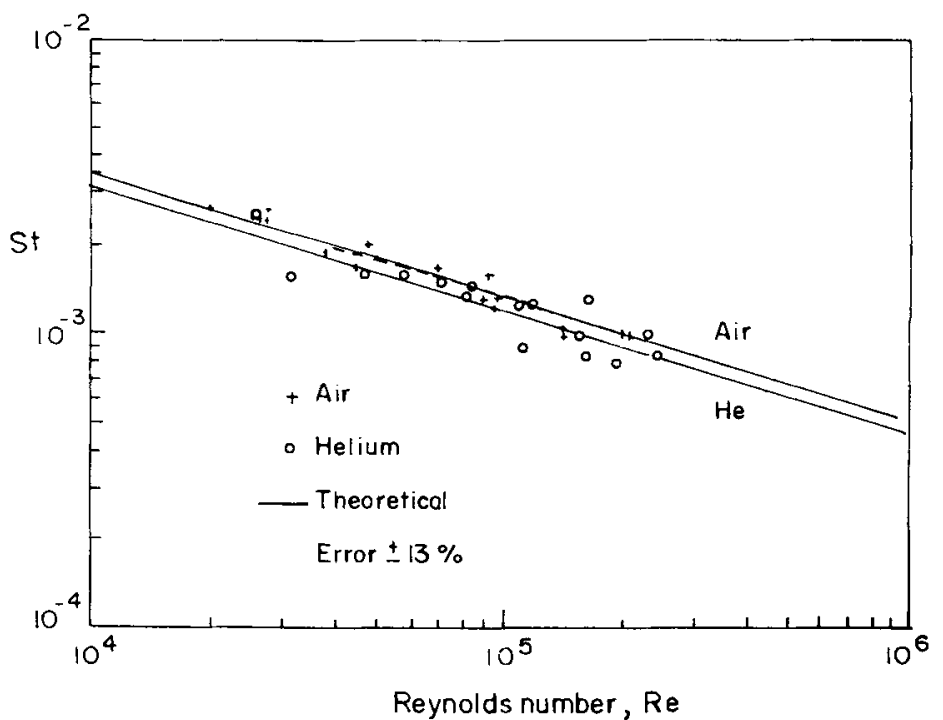

Figure 10. Variation of the heat transfer coefficient with Reynolds number over the surface of a flat plate.

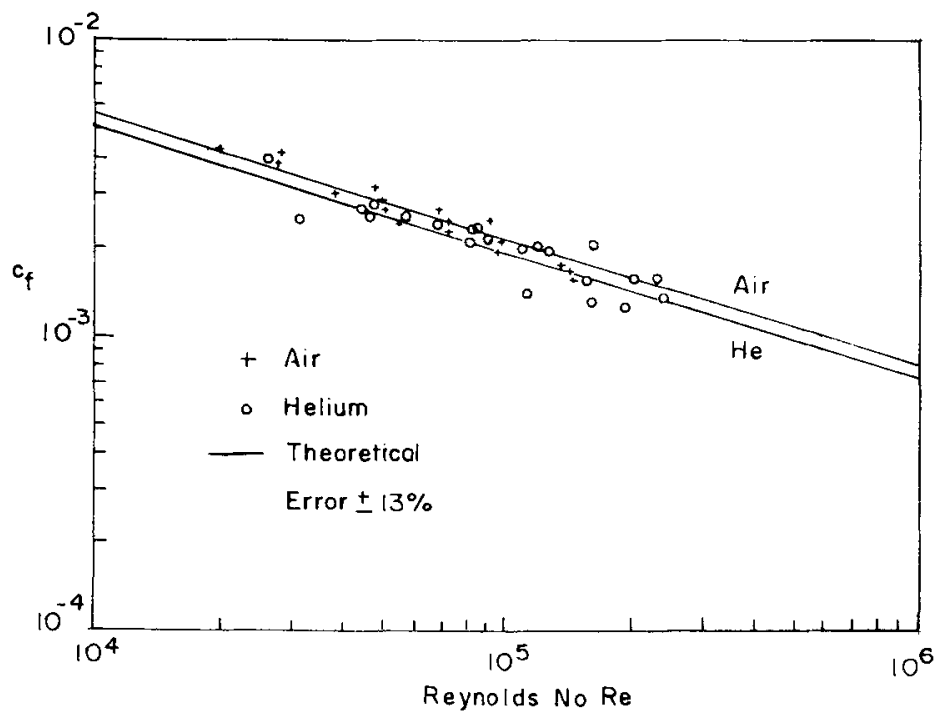

Figure 11. Variation of the skin friction coefficient with Reynolds number over the surface of a flat plate. 


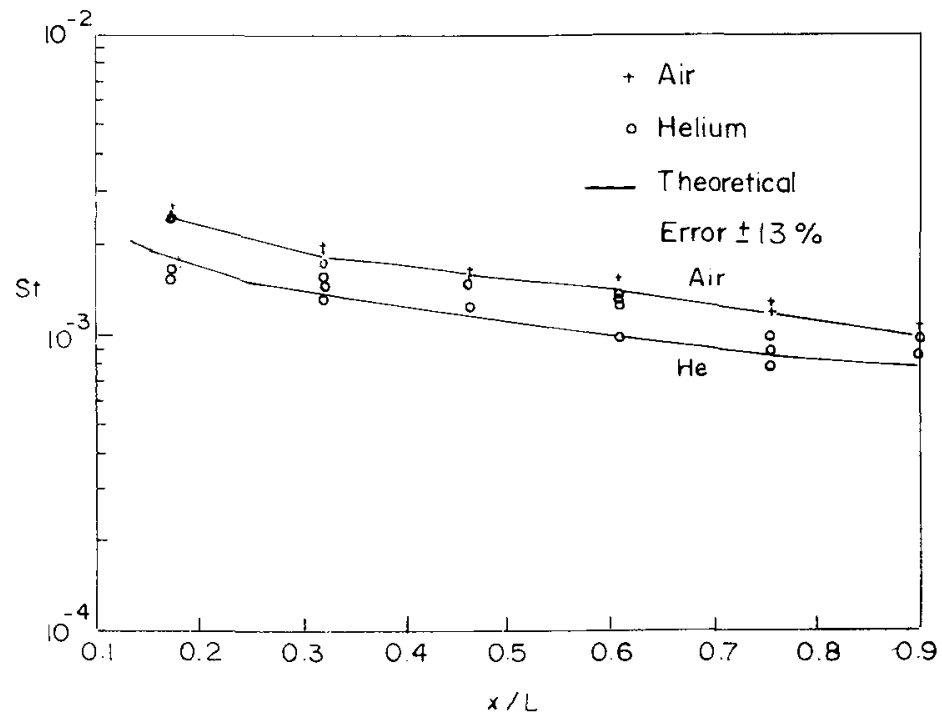

Figure 12. Variation of the heat transfer coefficient at different locations on the surface of a flat plate.

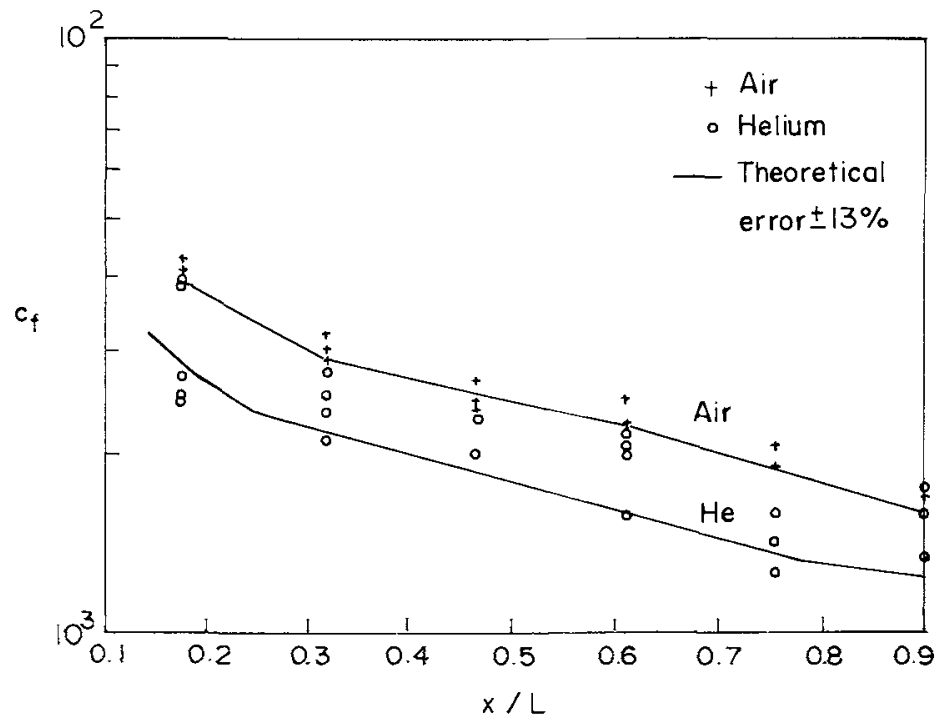

Figure 13. Variation of the skin friction coefficient at different locations on the surface of a flat plate. 


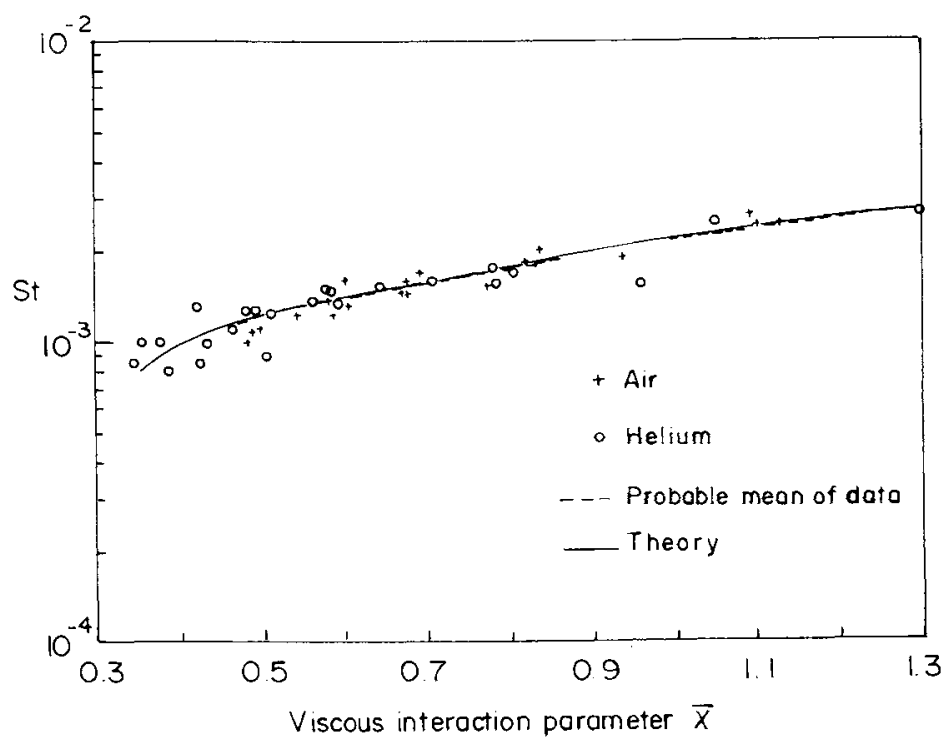

Figure 14. Variation of the heat transfer rate coefficient as a function of the viscous interaction parameter.

\subsection{Heat transfer rate measurements over an SLV-3 model}

The most important data generated in the HST1 tunnel soon after it was commissioned in 1975 were the heat transfer rates on an ISRO satellite launch vehicle SLV-3 model, shown schematically in figure 15, which experiences maximum heating at an altitude of approximately $14.7 \mathrm{~km}$ (Reddy \& Viswanath 1977). The corresponding flight conditions are Mach number 3.66 and velocity $1.08 \mathrm{~km} / \mathrm{s}$, Reynolds number $15.5 \times 10^{6} \mathrm{~m}^{-1}$ and total temperature of $800 \mathrm{~K}$. Hence heat transfer rates were measured in the HST1 tunnel at Mach numbers 4.0 and 5.5, with Reynolds number varying in the range $2 \times 10^{5}$ to $3 \times 10^{6} \mathrm{~m}^{-1}$.

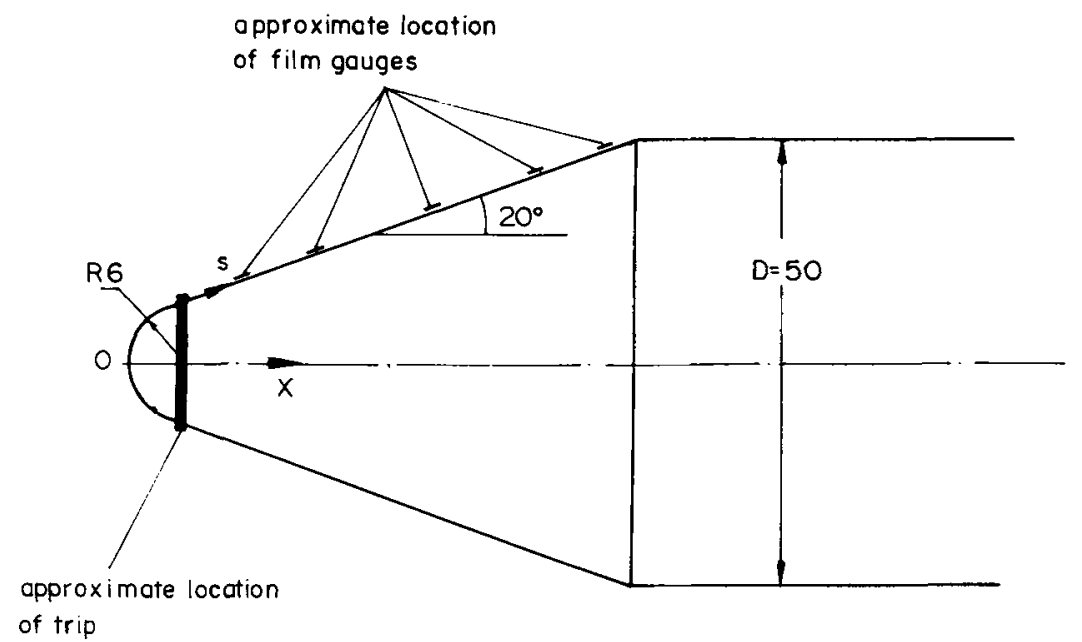

Figure 15. Schematic diagram of the SLV-3 model. 


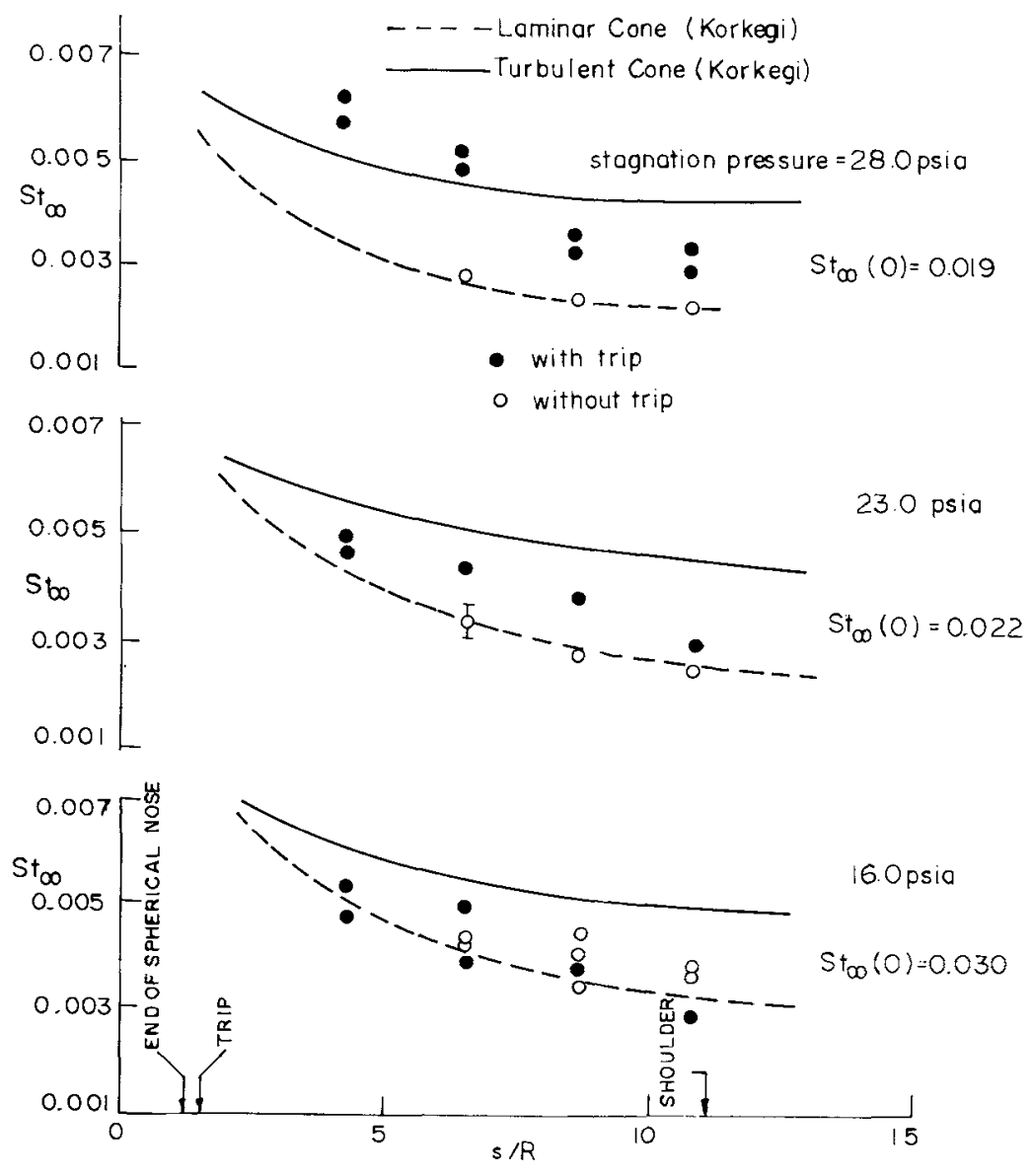

Figure 16. Distribution of the heat transfer rate coefficients on the nose cone.

The results of the measurement are presented in figure 16 in the form of Stanton number $\mathrm{St}_{\infty}$ (based on the freestream values of the flow field) along the conical surface of the SLV-3 nose cone. The Reynolds number in these measurements is low as air was used as the driver gas. The effect of a trip positioned at $s / R=1.4$ over the model has been found to show negligible effect at these low Reynolds number. The results are plotted in figures 17 and 18 in the form of local Stanton number (St) vs the Reynolds number $\left(u_{e} s / v_{e}\right)$ for Mach numbers 4 and 5.5 respectively. The higher Reynolds numbers were obtained using a combination of hydrogen driver gas and high driver pressures. Corresponding theoretical heat transfer rates predicted using flat plate theory with appropriate transformations for cone flow are also shown in these figures. For the laminar case, two estimates employing a certain reference temperature formula, as described by Korkegi (1962), are used. For the turbulent case, two estimates have been made: (i) by the method of Korkegi (1962) which again uses a certain reference temperature and (ii) by the Van Driest II formulation (Hopkins 1972). Theoretical estimates of Stanton numbers are based on the (local) cone Mach numbers of 1.8 and 1.9 at Mach 4 and 5.5 respectively, and the wall temperature ratio $T_{w} / T_{r}=0.4$ at both values of Mach numbers. 


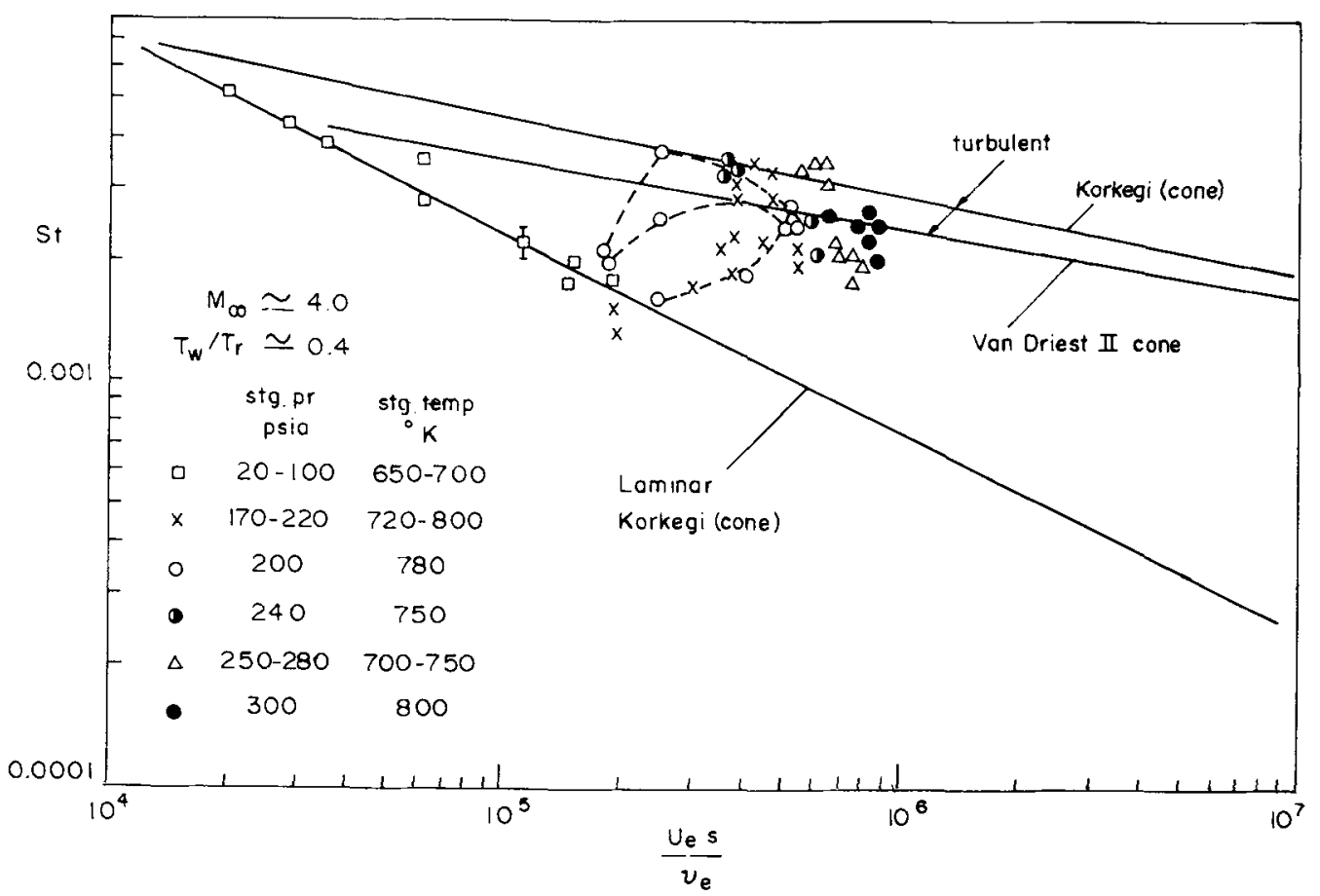

Figure 17. Heat transfer correlation with local Reynolds number at Mach 4.

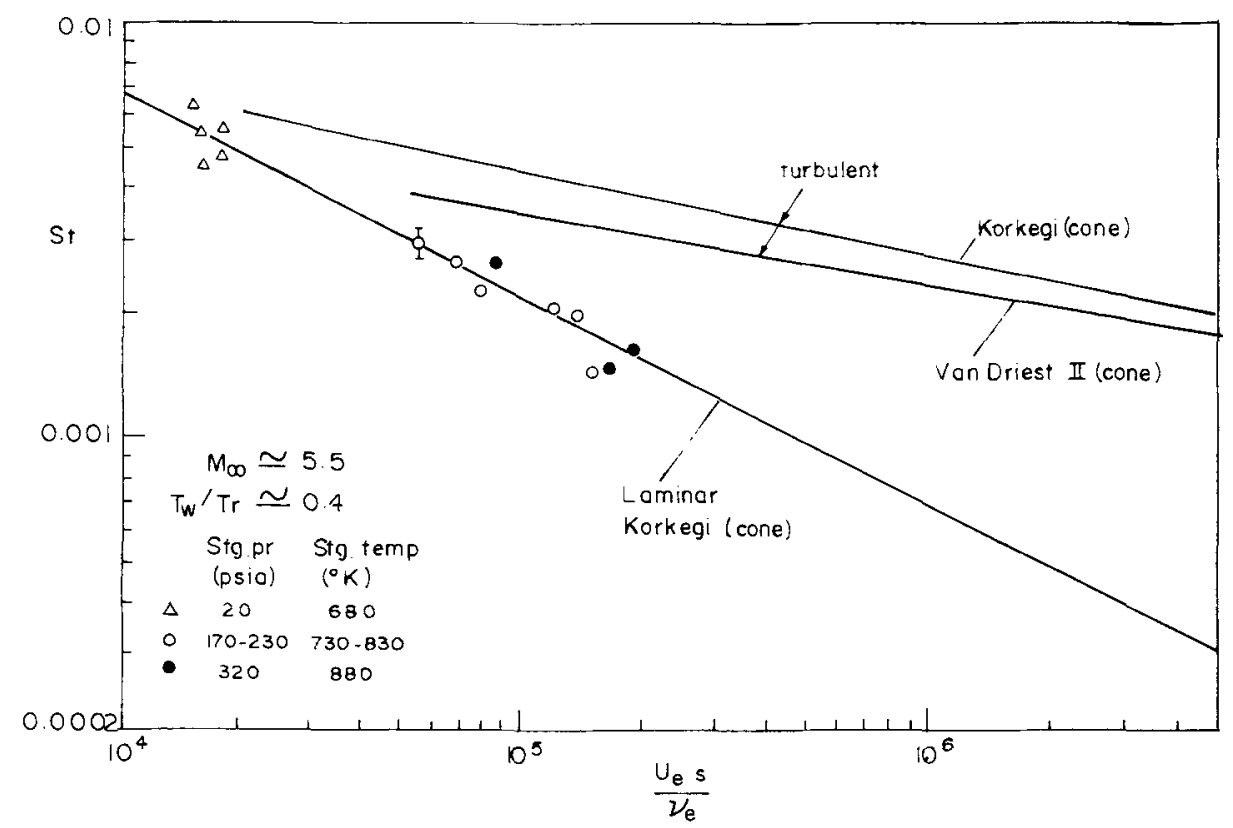

Figure 18. Heat transfer correlation with local Reynolds number at Mach 5.5. 


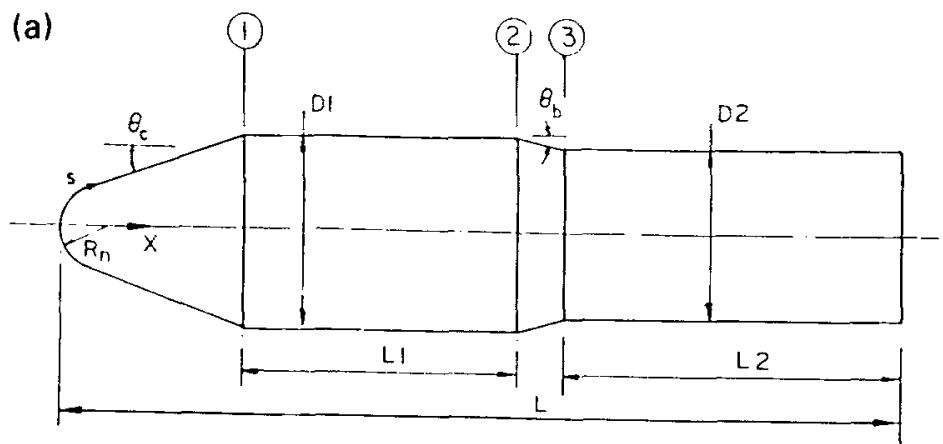

\begin{tabular}{|c|c|c|c|c|c|c|c|c|}
\hline $\begin{array}{c}\text { Model } \\
\text { (Model scole) }\end{array}$ & $\begin{array}{c}\text { OI } \\
(\mathrm{m} \mathrm{m})\end{array}$ & $\frac{\mathrm{R}_{\mathrm{n}}}{\mathrm{DI}}$ & $\begin{array}{c}\theta_{\mathrm{c}} \\
(\mathrm{deg})\end{array}$ & $\frac{\mathrm{L}_{1}}{\mathrm{D}_{1}}$ & $\begin{array}{c}\theta_{\mathrm{b}} \\
(\mathrm{deg})\end{array}$ & $\frac{\mathrm{DI}}{\mathrm{D} 2}$ & $\frac{\mathrm{L} 2}{\mathrm{D} 2}$ & $\begin{array}{c}\mathrm{L} \\
(\mathrm{m} \mathrm{m})\end{array}$ \\
\hline $\begin{array}{c}\text { I HEAT } \\
\text { TRANSFER } \\
(1 \mathrm{64})\end{array}$ & 500 & 02188 & 20 & 1.4062 & 15 & 1.1429 & 1.500 & 195 \\
\hline $\begin{array}{c}\text { II PRESSURE } \\
(1: 75)\end{array}$ & 42.66 & 02188 & 20 & 1.4062 & 15 & 1.1429 & 1.33 & 160 \\
\hline $\begin{array}{c}\text { UI FORCE 8 } \\
\text { OIL FLOW } \\
(1.80)\end{array}$ & 40.0 & 0.2188 & 20 & 1.4062 & 15 & 1.1429 & 2.323 & 185 \\
\hline
\end{tabular}

\begin{tabular}{|c|c|c|c|}
\hline Slation & 1 & 2 & 3 \\
\hline$X / R_{n}$ & 4.357 & 10.786 & 11845 \\
\hline$s / R_{n}$ & 5.157 & 11.584 & 12.693 \\
\hline$x / 02$ & 1.089 & 2.697 & 2.961 \\
\hline
\end{tabular}

(b)
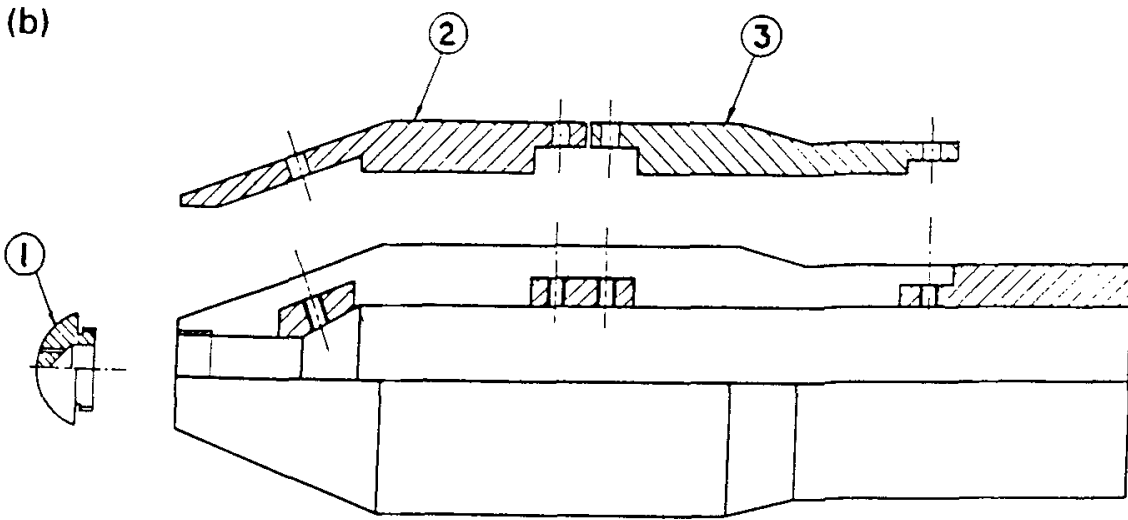

ALUMINIUM

(1),(2), (3) ARE MACOR INSERTS

Figure 19. Schematic diagram of the bulbous heat shield model (a), with the Macor inserts for the heat transfer gauges (b). 
(b)

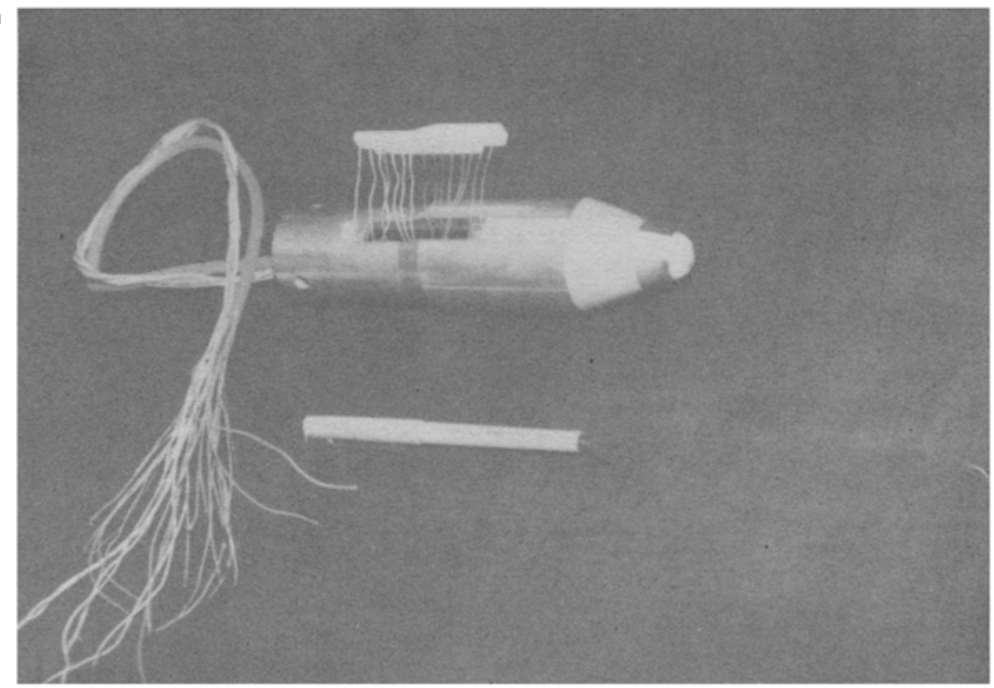

(a)

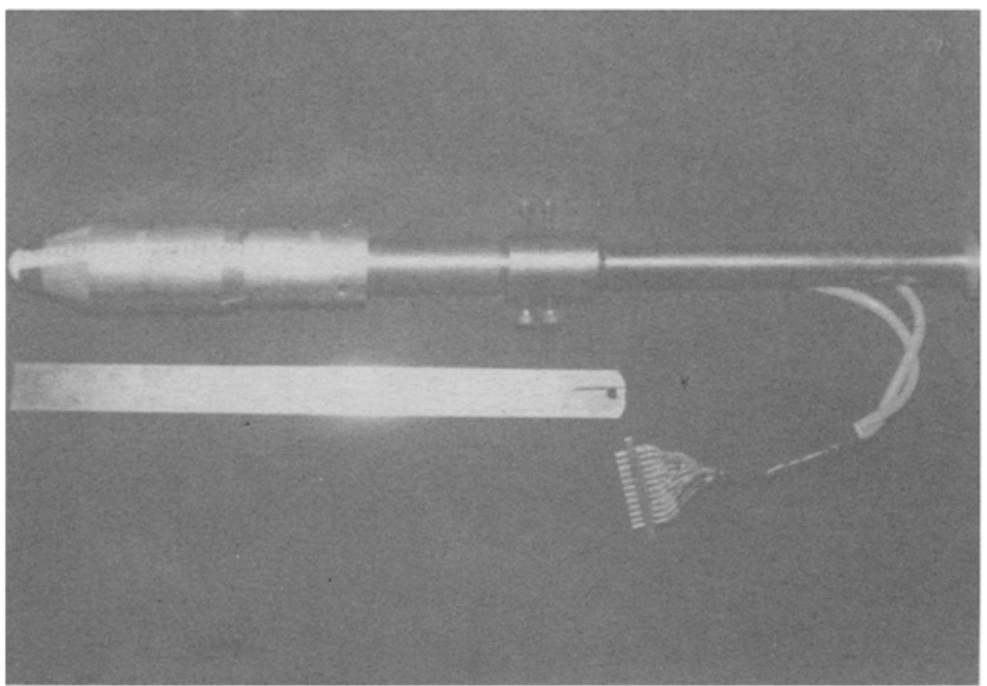

Figure 20. (a) Photograph of the bulbous heat shield model with the gauges. (b) Electrical leads from the gauges are shown.

Results presented in figures 16 to 18 show that, at relatively low Reynolds number, the measured heat transfer rates are in very good agreement with the theory for laminar flow at both freestream Mach numbers. At Mach 4.0, natural transition to turbulent flow occurs around a local Reynolds number of $2 \times 10^{5}$. The measured data after some overshoot in the transition region appear to settle down to values predicted by Van Driest II at higher Reynolds numbers. At Mach 5.5, on the other hand, there is no sign of transition to turbulence in the range of Reynolds numbers covered in the experiments.

Thus, in conclusion, the above investigations have shown that at Mach 4 the Van Driest II flat plate theory for turbulent boundary layer (Hopkins 1972), with appropriate modifications for the cone flow, may be used to get reasonable estimates of heat flux on the 


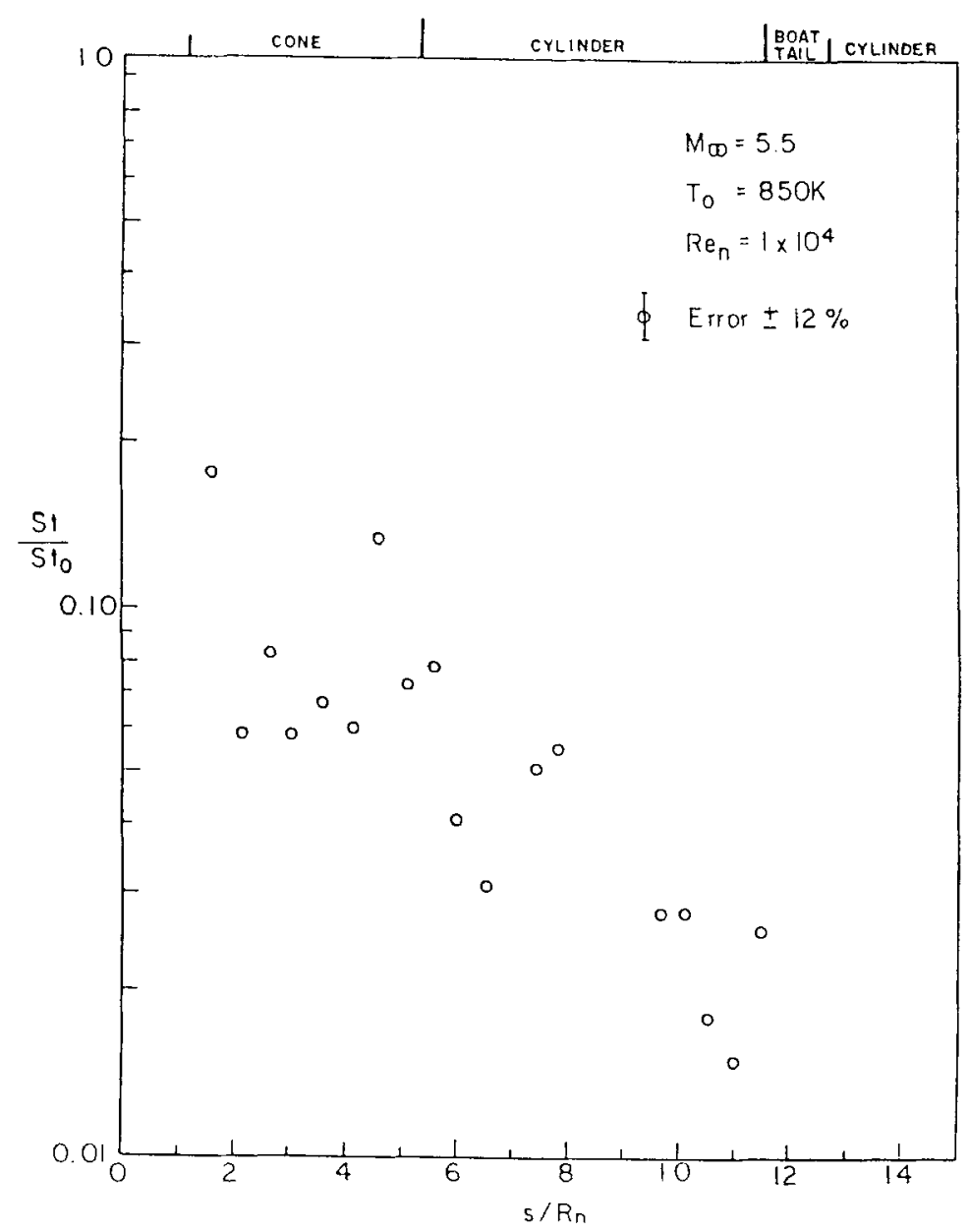

Figure 21. Windward side heat transfer rate distribution at $0^{\circ}$ angle of attack using nitrogen driver gas

conical surface at high Reynolds numbers. Also, at Mach 5.5 no transition to turbulence flow occurs at the low Reynolds numbers considered in the above investigations.

\subsection{Heat transfer measurements over a bulbous heat shield model of a launch vehicle (PSLV)}

Satellite launch vehicles usually have bulbous heat shield configurations in order to be able to launch satellites of different shapes and sizes. Estimation of hypersonic flow fields over such geometries at hypersonic Mach numbers is extremely complex, especially at an angle of attack. Theoretical analysis of such flow fields would be a Herculean task demanding extremely powerful computer systems with very advanced numerical algorithms. An alternative is to measure the aerodynamic data experimentally using hypersonic shock tunnels. 


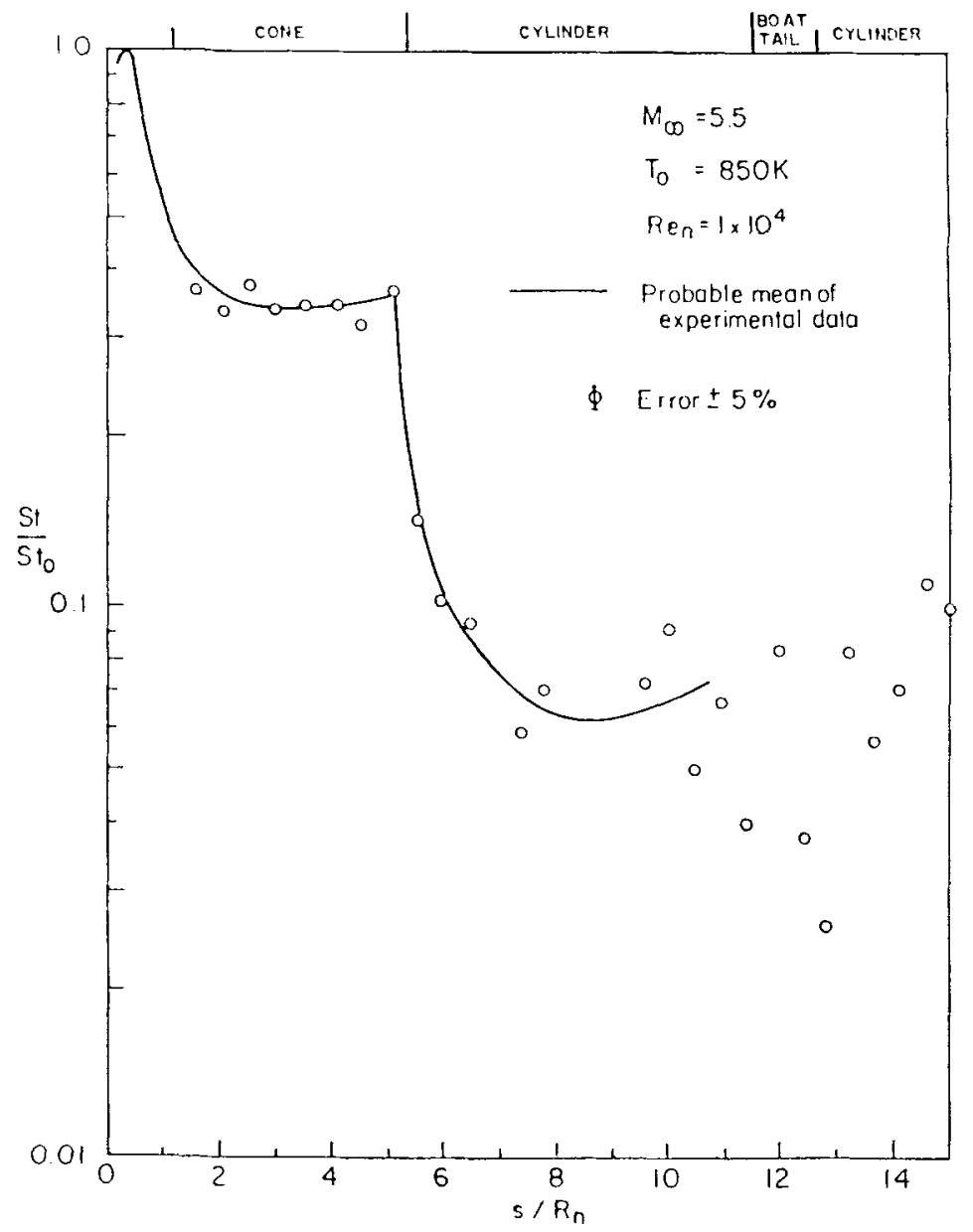

Figure 22. Windward side heat transfer rate distribution at $10^{\circ}$ angle of attack using nitrogen driver gas.

Detailed heat transfer measurements have been made on the bulbous nose cone model in the HST1 tunnel at freestream Mach number 6, total temperature $1830 \mathrm{~K}$ and Reynolds number (based on the nose radius) up to $2.5 \times 10^{4}$ (Reddy et al 1988; Reddy \& Srinivasa 1990; Srinivasa 1991). Here, the lower values of the Reynolds number were obtained using nitrogen as the driver gas, while the higher values were obtained with hydrogen as the driver gas.

The blunt cone-bulbous heat shield model used for the heat transfer measurements is shown in figure 19a and is a scale model of the PSLV nose cone. The $195 \mathrm{~mm}$ long and $50 \mathrm{~mm}$ diameter model is fabricated using aluminium alloy with cut-outs for insertion of the heat transfer gauges. The spherical nose cap is made of the insulating backing material so that one of the thin film heat transfer gauges of about $5 \mathrm{~mm}$ length can be formed at the stagnation region. For these studies a machinable glass material called Macor is used, for the first time in India, as the insulating backing material. This special glass material has nearly the same properties as Pyrex glass but has the additional attractive property 


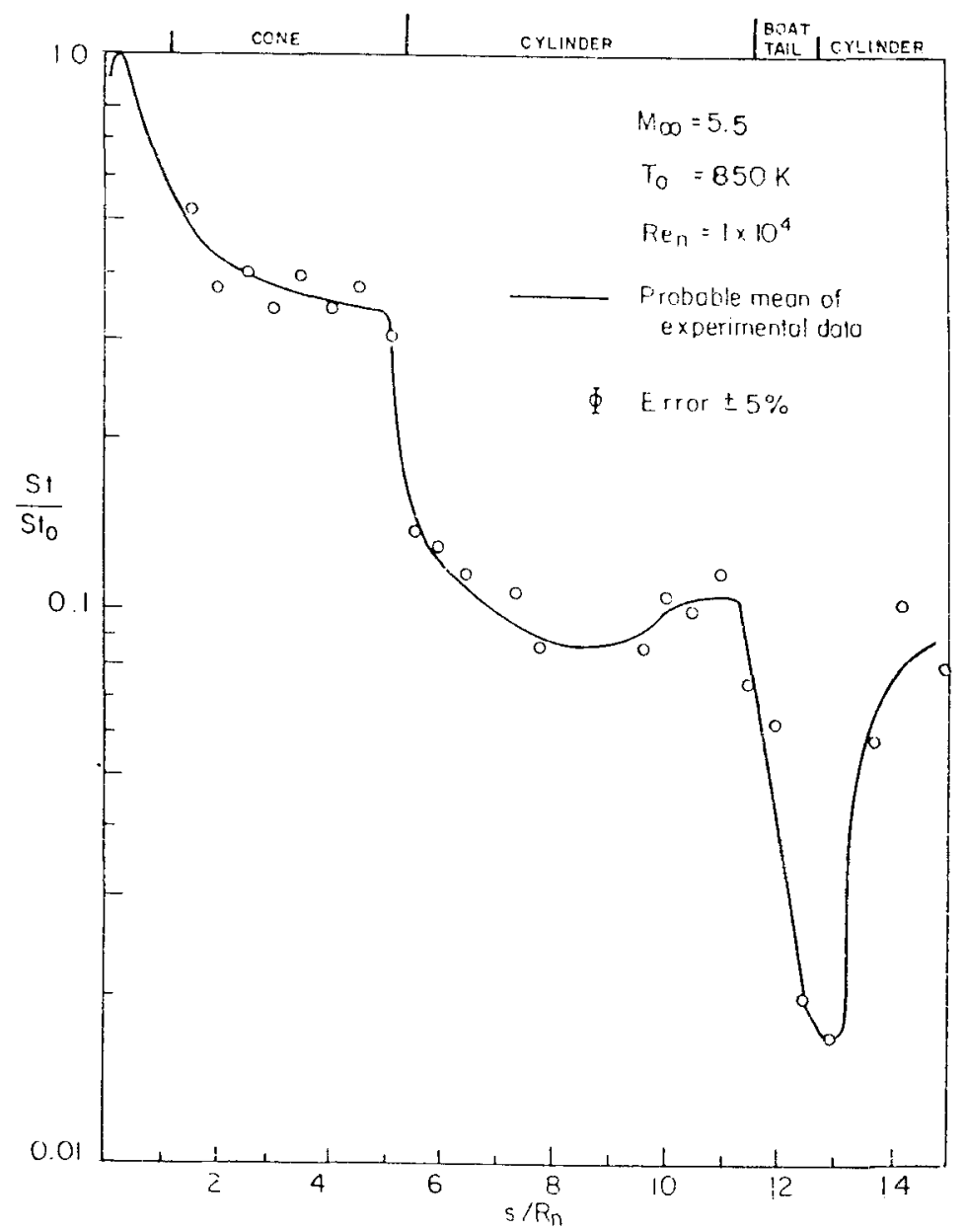

Figure 23. Windward side heat transfer rate distribution at $17^{\circ}$ angle of attack using nitrogen driver gas.

of machinability. Therefore, unlike Pyrex glass, any intricate model shapes can be easily formed out of this material and thus it can be used as backing material for heat transfer gauges. Thus the geometric similarity of heat transfer models can be achieved easily. The gauges are found to be more durable than gauges made using Pyrex glass as backing material. Macor gauge inserts of $10 \mathrm{~mm}$ width along the body of the model are made in two pieces as shown in figure 19b, so that in case of damage to some of the gauges, that piece alone needs to be replaced. Photographs of an instrumented model are shown in figure 20. The instrumented model can be mounted in the test section at angles of attack in the range $-18^{\circ}$ to $+18^{\circ}$ and at any roll angle, so as to measure the heat transfer rate distribution over the entire model.

A series of tests have been conducted initially using nitrogen as driver gas in order to measure heat transfer rates at low total temperature, which ensures perfect gas-like behaviour of the test gas. In these tests, typical static pressures and temperatures are $400 \mathrm{~N} / \mathrm{m}^{2}$ and $850 \mathrm{~K}$ respectively and the freestream Reynolds number based on the nose 


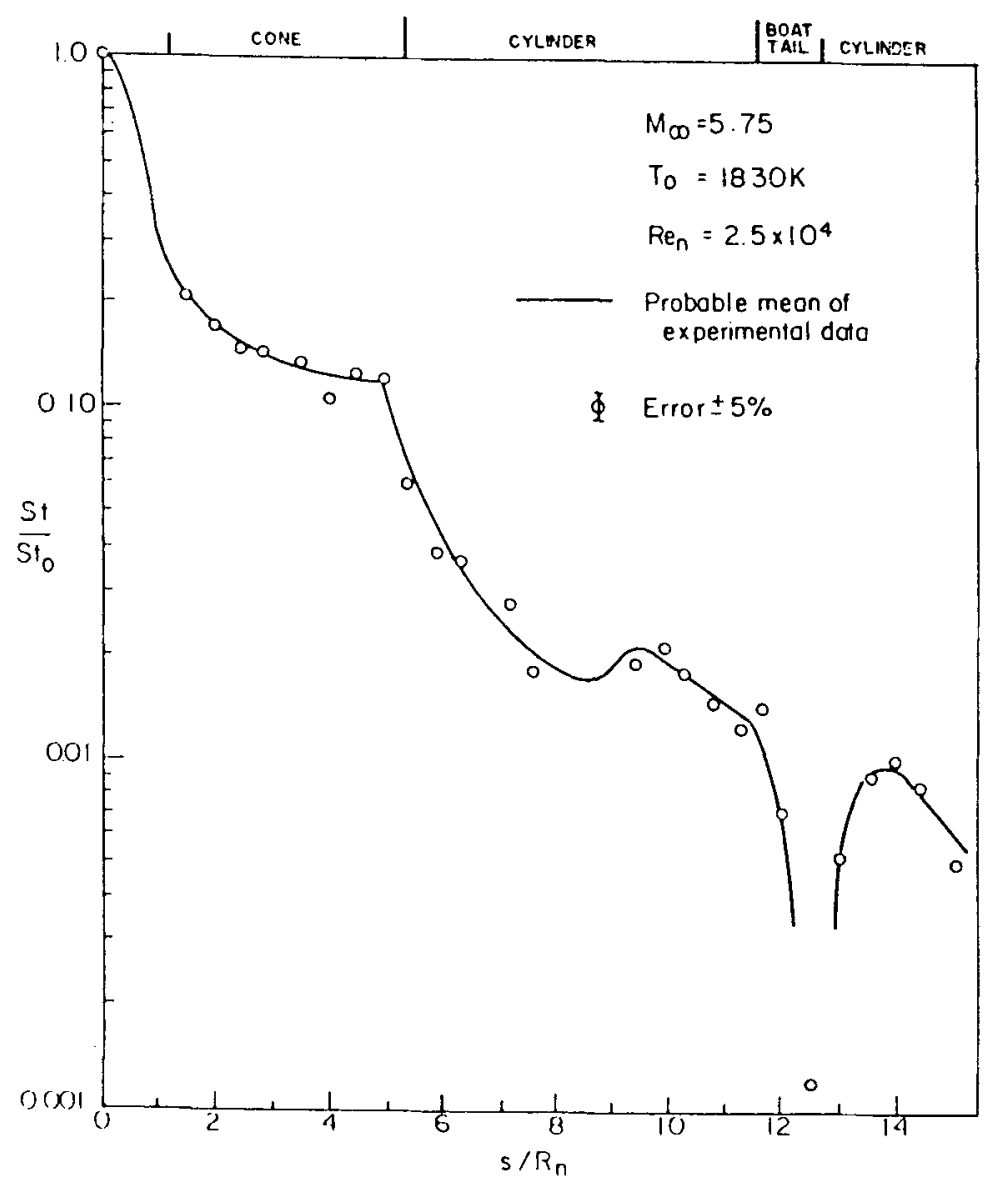

Figure 24. Heat transfer rate distribution at $0^{\circ}$ angle of attack using hydrogen driver gas.

radius is about $1 \times 10^{4}$. These low temperature tests were undertaken essentially to ascertain the functioning of the analogue network used for converting the temperature signal from the heat transfer gauges to heat transfer signals. However, typical satellite launch vehicle ascent flight conditions at Mach number 5.5 are $\mathrm{Re}_{n}$ of $2.8 \times 10^{4}$ and total temperature of $1700 \mathrm{~K}$. Hence a second series of tests were conducted at freestream conditions close to these values using hydrogen as driver gas, which yields a freestream test Mach number of 5.75 and Reynolds number of $2.5 \times 10^{4}$ based on nose radius and a stagnation temperature of $1830 \mathrm{~K}$.

The heat transfer data measured along the windward generator $\left(\phi=0^{\circ}\right)$ at angles of attack $0^{\circ}, 10^{\circ}$ and $17^{\circ}$ with nitrogen as driver gas are shown in figures 21 to 23 respectively. Heat transfer rate data are plotted as Stanton number along the surface of the model normalised with respect to the stagnation point Stanton number estimated using the Fay \& Riddel (1958) method. Corresponding data using hydrogen as driver gas are presented in figures 24 to 26 . Heat transfer data along the leeward side $\left(\phi=180^{\circ}\right)$ measured for $10^{\circ}$ and $17^{\circ}$ angles of attack with hydrogen driver gas are shown in figures 27 and 28 , respectively. 


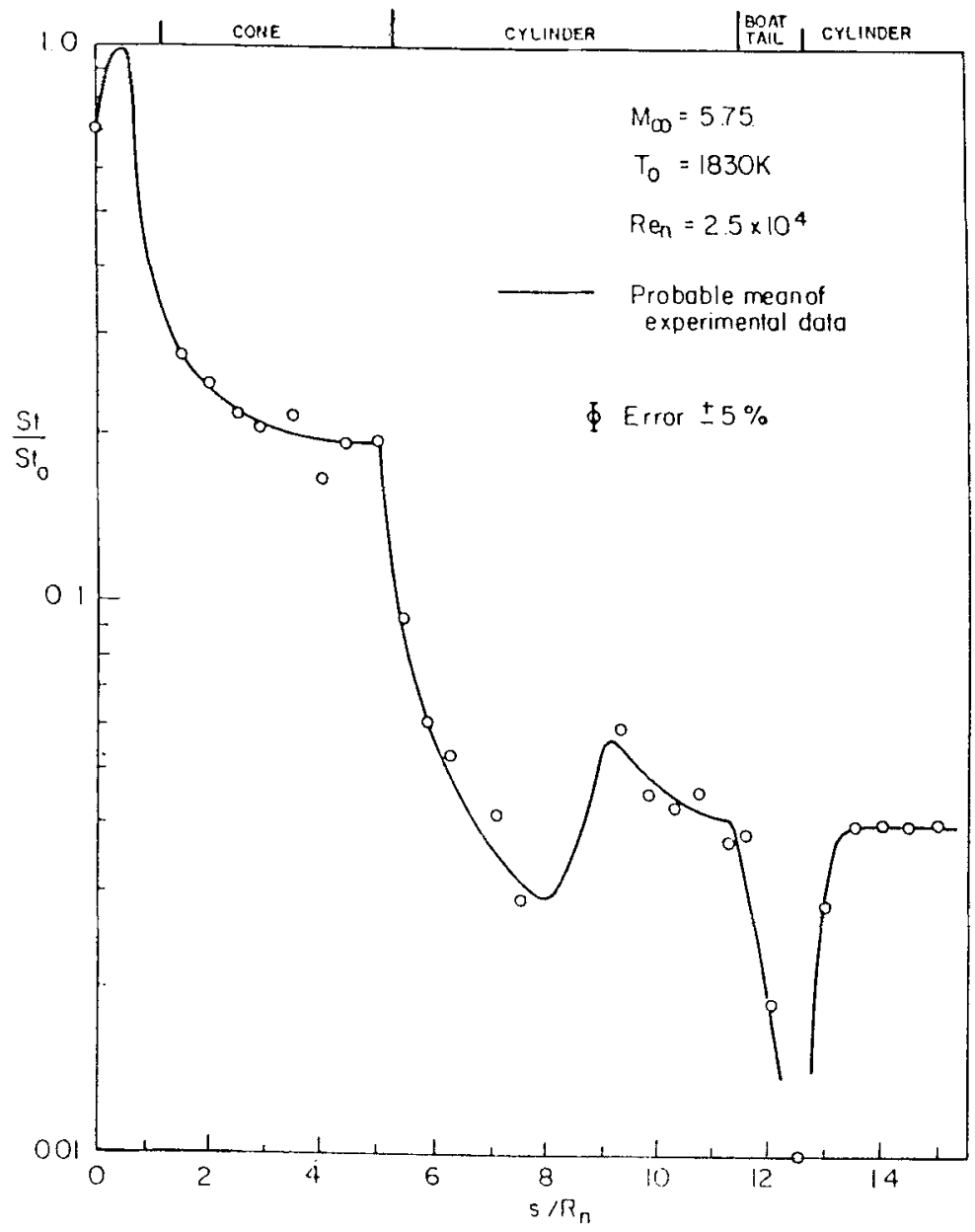

Figure 25. Windward side heat transfer rate distribution at $10^{\circ}$ angle of attack using hydrogen driver gas.

The scatter in the measured heat transfer rates for $0^{\circ}$ angle of attack (figure 21) is due to the high noise level in the analogue network for heating rates below $1 \mathrm{~W} / \mathrm{cm}^{2}$ obtained for nitrogen driver gas. Figures 22 and 23 show that at higher angles of attack the heat transfer rates are high over the cone on the windward side and that scatter is reduced considerably. The boat tail-cylinder compression corner effect enhancing the heating rate is also seen in these figures. A possible interaction of boundary layer with compression waves arising from the interaction of the Prandtl-Meyer expansion waves with the bow shock wave is indicated by the lower heating rates over the first cylinder, after the cone-cylinder junction, as compared with further downstream values. In case of hydrogen driver gas the windward data at $0^{\circ}$ angle of attack of figure 24 shows that heating rates at the cone-cylinder and cylinder-boat tail junction reduce as expected due to Prandtl-Meyer expansions. Also the results indicate that, over the first cylinder, the boundary layer thickness increases immediately downstream of the cone-cylinder junction and decreases subsequently, which is inferred from the decrease and increase of the heat transfer rate coefficient. The windward 


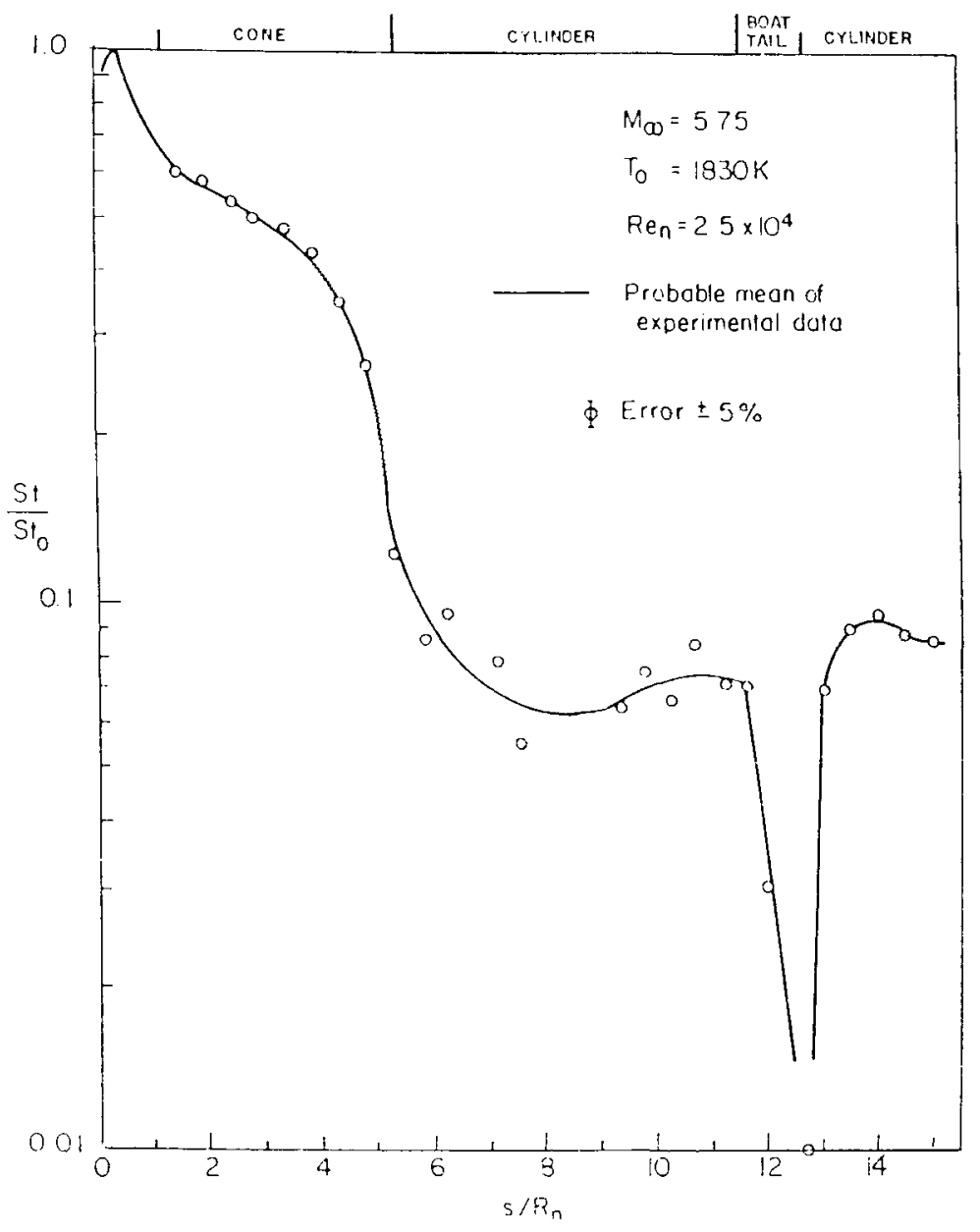

Figure 26. Windward side heat transfer rate distribution at $17^{\circ}$ angle of attack using hydrogen driver gas.

side heating rates at $10^{\circ}$ angle of attack shown in figure 25 are higher than the corresponding heating rates for $0^{\circ}$ angle of attack, but show a similar trend. On the first cylinder, the interaction of reflected compression waves with the boundary layer also occurs at this angle. These results indicate the existence of a small separation bubble at the boat tailcylinder junction. Also, at this angle of attack the compression corner appears to have a fairly strong shock giving rise to appreciable jump in heat transfer rate. At $17^{\circ}$ angle of attack the windward side heating rates shown in figure 26 are significantly high, especially over the cone ( $20^{\circ}$ half-angle) where they are close to stagnation point heating rates. The drop in heating rates due to Prandtl-Meyer expansion at the cone-cylinder junction appears to have begun over the cone itself and the expansion is no longer centred but has spread out over the other side of the junction. Here also high heating rates over the first cylinder and interaction of compression waves with boundary layer are seen. The flow is found to be fully attached on the windward side. 


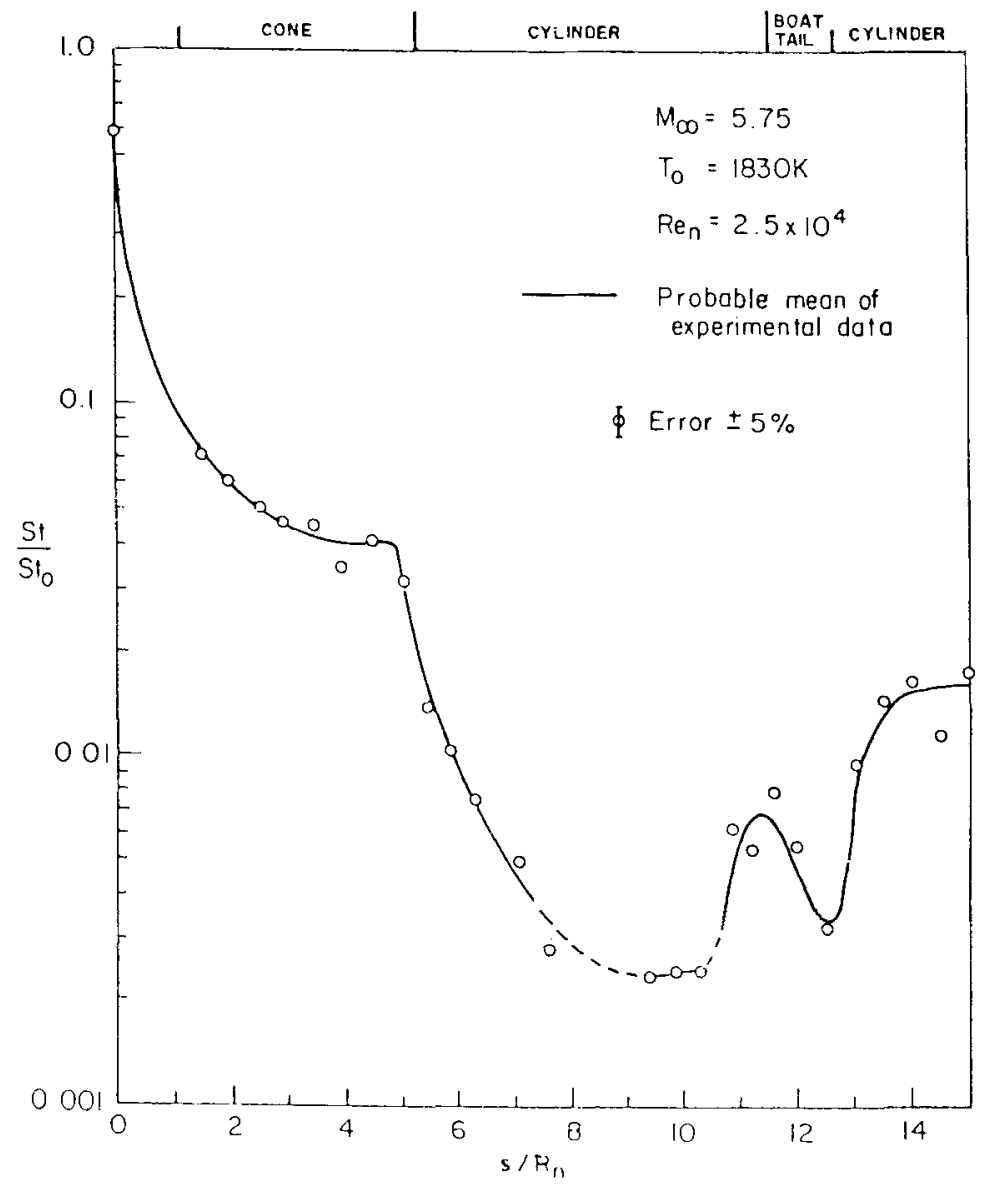

Figure 27. Leeward side heat transfer rate distribution at $10^{\circ}$ angle of attack using hydrogen driver gas.

Leeward side heating rates for both $10^{\circ}$ and $17^{\circ}$ angle of attack (figures 27 and 28) are lower than the corresponding values for the windward side. For $10^{\circ}$ angle of attack, the heating rates are very low - between $s / R_{n}=7.5$ and 10 - indicating separation of flow. Higher heating rates are observed at the end of the cylinder, probably due to reattachment of the flow. This reattachment enhances the heating rates over the second cylinder appreciably. At $17^{\circ}$ angie of attack the crossflow separation appears to have moved slightly upstream as compared to that at $10^{\circ}$ angle of attack, as shown in figure 28 . However, towards the aft end of the first cylinder, heating rates are higher than those for $10^{\circ}$ angle of attack, which is due to significant reattachment flow at this higher angle of attack.

Experimental heat transfer rates are compared with the data computed for zero angle of attack in figure 29. The computations are made using 2-D boundary-layer code (Tobak $\&$ Peake 1979) and viscous shock-layer code (Swaminathan 1983). The predicted heating rates match very well with the experimental rates in general, the viscous shock-layer results being closer to the measured values than the 2-D boundary layer results. 


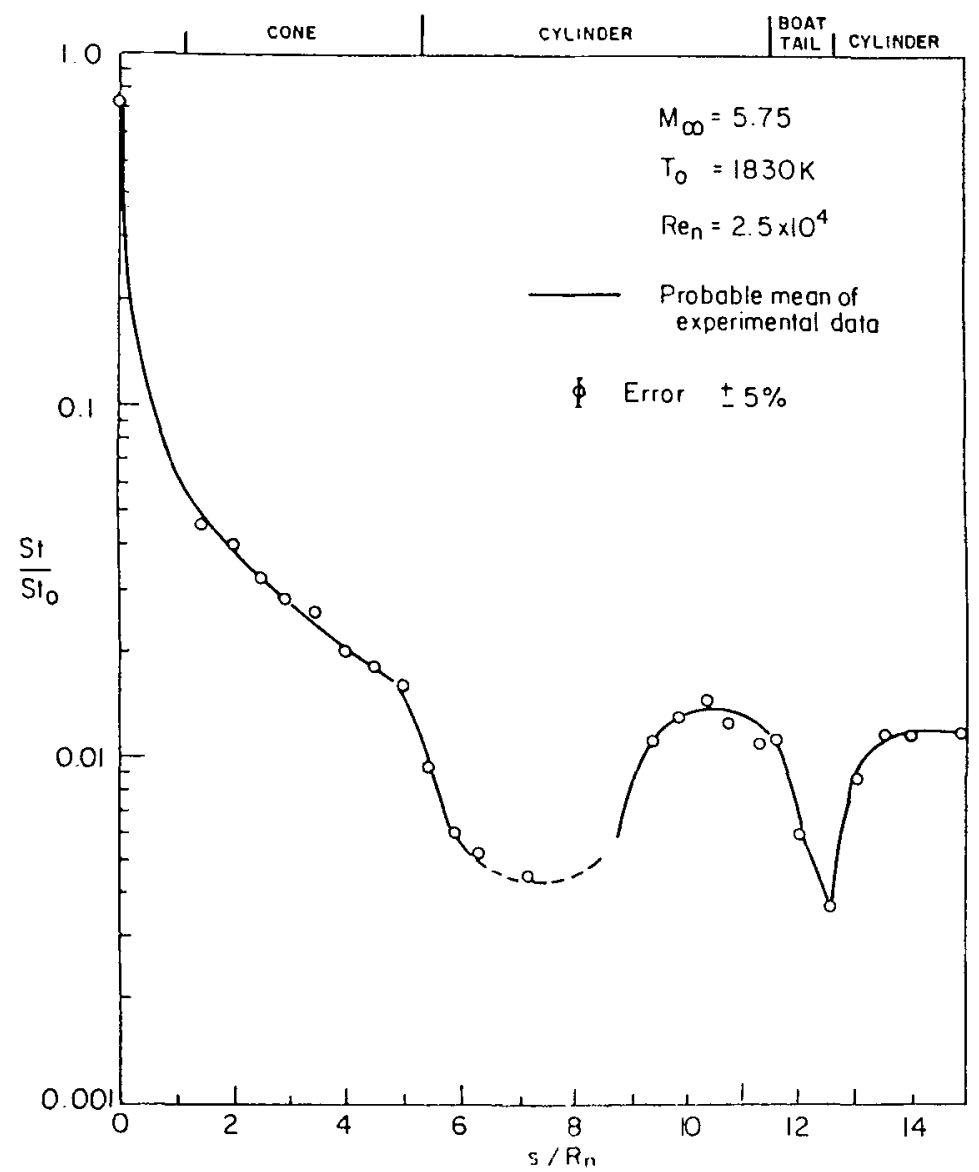

Figure 28. Leeward side heat transfer rate distribution at $17^{\circ}$ angle of attack using hydrogen driver gas.

\section{Flow visualization using electrical discharge technique}

Visualization of the complex flowfields around the hypersonic vehicles is an important aspect of the experimental reentry aerodynamics. This is conventionally achieved by employing optical systems, such as the schlieren method, interferometry, shadowgraphs and holography. Except for holography none of the other systems is useful for three-dimensional shock wave visualization because the visualization in these systems is achieved by passing light along the optical axes perpendicular to the direction of the gradient of gas density. On the other hand, the holographic technique is very sensitive to mechanical vibrations and hence is very difficult to use for flow visualization in wind tunnel tests. In addition, since the run time and freestream densities of the test gas in the test section of the hypersonic shock tunnel are very low, flow visualization using the above techniques is extremely difficult.

We have recently developed a new electrical discharge technique to visualize the hypersonic flowfields around the test models in an hypersonic shock tunnel (Jagadeesh $e t$ al 1996). The basic principle of this technique is that spontaneous light emission from 


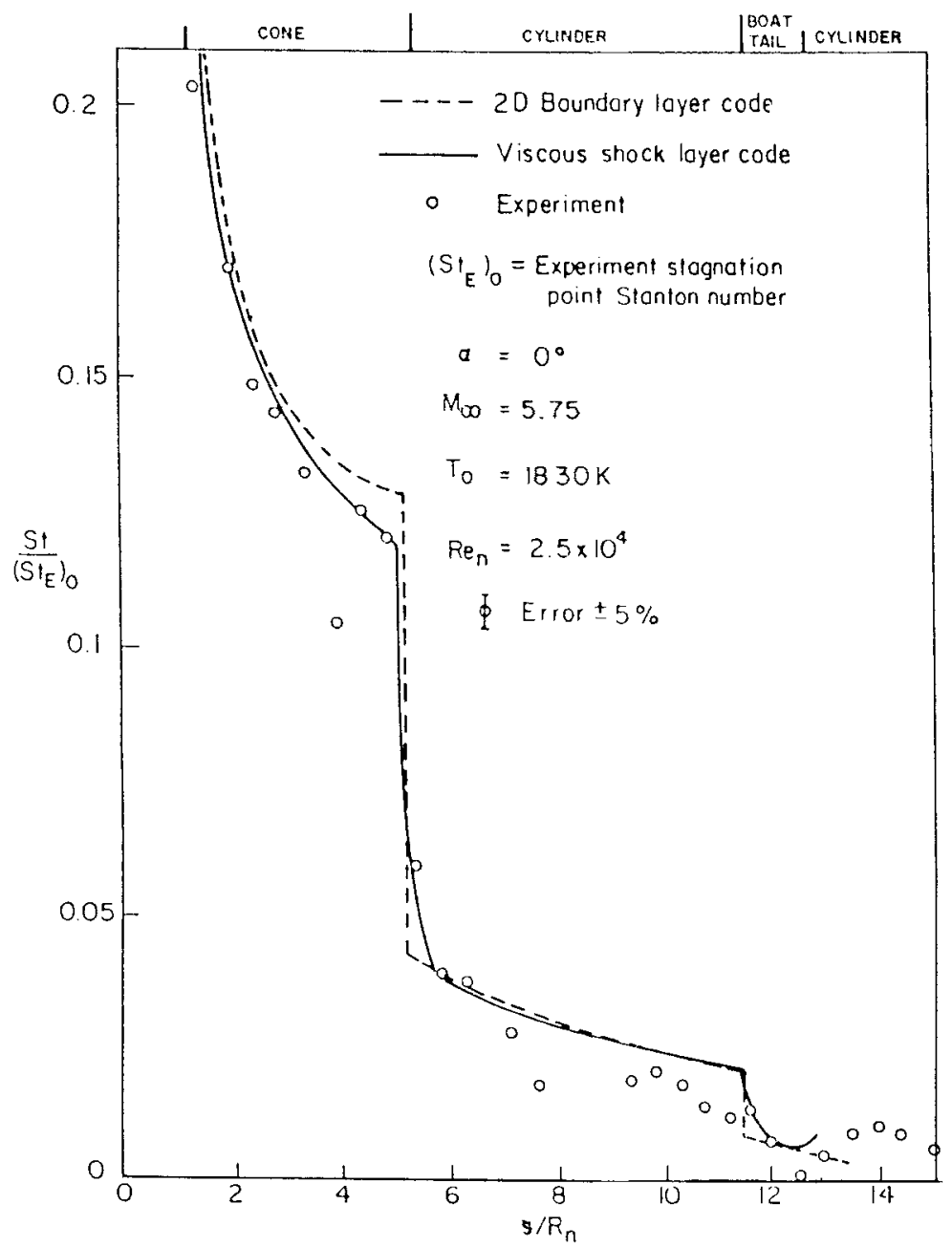

Figure 29. Comparison of experimental heat transfer rates with the predicted values at $0^{\circ}$ angle of attack.

a discharge zone is dependent on local gas density. Hence, when an electrical discharge takes place across a shock wave, the position of the shock wave can be clearly seen, as the light intensity from the shock wave is different from that of the freestream or the shock layer. The flowfield around a flat plate with a sharp leading edge and at an angle of attack visualized using this technique in the HST1 shock tunnel at Mach 5.75 is shown in figure 30 . This technique can be extended for three-dimensional flow visualization by appropriate arrangement of the electrodes and by taking the photograph of the electrical discharge either in the downstream or upstream direction of the flow.

\section{Enhancement of performance capabilities of HST1}

As is evident from the above results, one of the serious limitations of the HST1 in its current form is the limitation in the Reynolds number simulation. The Mach number 


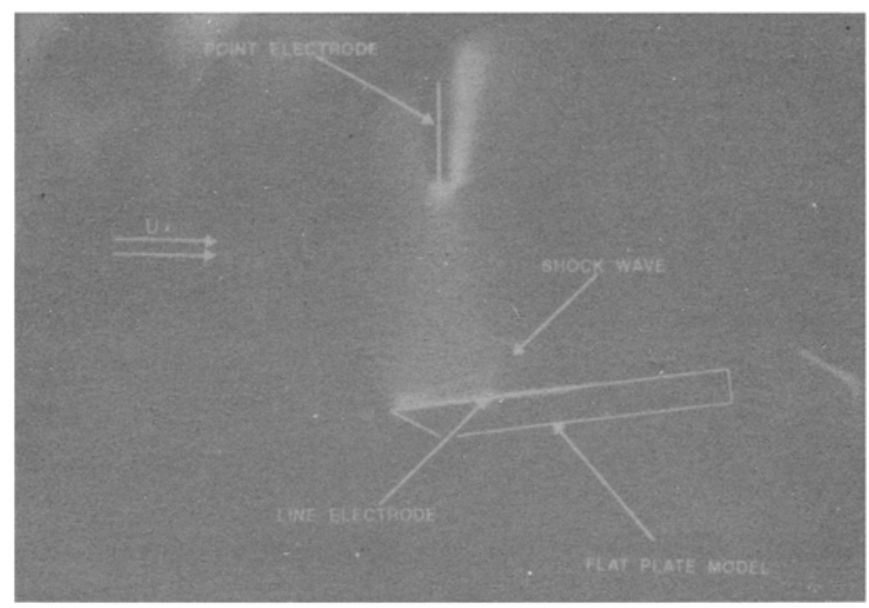

Figure 30. The flow field around a tlat plate with a sharp leading edge at $6^{\circ}$ angle of attack visualized using the electrical discharge technique. The flow conditions are: Mach number $=5.75$, freestream temperature $=173 \mathrm{~K}$ and freestream density $=1.0 \times 10^{-2} \mathrm{~kg} / \mathrm{m}^{3}$.

limitation is overcome by the addition of the wind tunnel portion to the shock tube. However, enhancement of the Mach number beyond a specific value would reduce the density in the test section drastically. One way to improve the performance capabilities is to increase the temperature and the pressure of the test gas in the stagnation chamber before the nozzle entrance. This can be achieved by increasing the strength of the shock wave in the shock tube by using higher pressure difference across the primary diaphragm. Currently, since the shock tube is made of aluminium, the pressure in the driver section cannot be increased to higher values. Hence, to overcome this limitation, we have planned to strengthen the shock tube by adding a stainless steel jacket to the entire length of the tube. This would ensure enhancement of shock tube performance with minimum fabrication work.

Real gas effects are more effectively simulated in another version of the shock tunnel known as free-piston driven shock tunnel (FPST), which is also referred to as the hypervelocity shock tunnel, since in this tunnel the velocity of the flow is simulated instead of the Mach number (Reddy et al 1993, 1994). The basic design of an FPST is shown schematically in figure 31 . In this tunnel helium driver gas is preheated to about $5000 \mathrm{~K}$ by

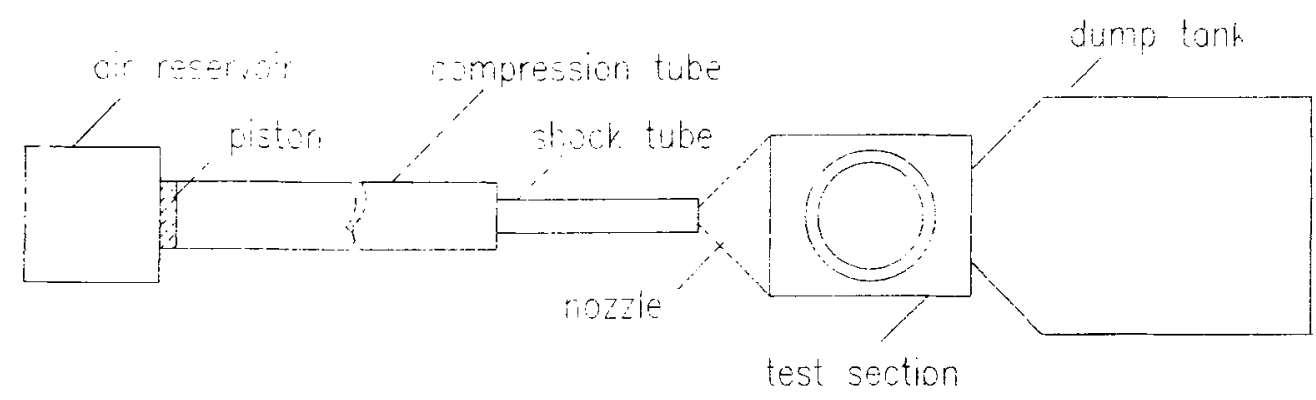

Figure 31. Schematic diagram of the proposed IISc free piston driven hypersonic shock tunnel. 
Table 3. Specifications of the proposed IISc free piston-driven hypersonic shock tunnel.

\begin{tabular}{lc}
\hline Parameter & Value \\
\hline Diameter of the compression tube & $0.165 \mathrm{~m}$ \\
Diameter of the shock tube & $0.036 \mathrm{~m}$ \\
Length of the compression tube & $10.0 \mathrm{~m}$ \\
Length of the shock tube & $4.5 \mathrm{~m}$ \\
Volumetric compression ratio & 60.0 \\
Mass of the piston & $20.3 \mathrm{~kg}$ \\
Initial pressure of air in the reservoir & $66.5 \mathrm{~atm}$ \\
Typical shock Mach number & 18 \\
Pressure at the diaphragm rupture & $948 \mathrm{~atm}$ \\
Temperature at the diaphragm rupture & $4693 \mathrm{~K}$ \\
Typical estimated stagnation enthalpy & $45 \mathrm{MJ} / \mathrm{kg}$ \\
Typical estimated test section flow velocity & $9.5 \mathrm{~km} / \mathrm{s}$ \\
\hline
\end{tabular}

an adiabatic compression in the compression tube which produces shock Mach numbers, $\mathrm{M}_{s} \sim 15$. Specific stagnation enthalpies exceeding $10 \mathrm{MJ} / \mathrm{kg}$ are commonly achieved in these tunnels. Installation of an FPST with the specifications given in table 3 at the Indian Institute of Science is under progress.

In all the measurements reported in this review the wind tunnel portion of the HST1 was made out of mild steel. An important requirement of the flow simulations in the wind tunnels is to maintain very clean test gas. To ensure this condition in the tunnel the inner portion of the wind tunnel section was coated with a special paint to eliminate rust problems. However, to completely eliminate the rust problem we have recently added a new wind tunnel section made of stainless steel along with a new pumping system capable of achieving vacuum levels of $10^{-6}$ mbar in a short time to enhance the turn around time.

\section{Conclusions}

The importance of a hypersonic shock tunnel for laboratory simulation of the flowfields around hypersonic space vehicles is highlighted. The capabilities and the performance characteristics of the hypersonic shock tunnel HST1 established at the Indian Institute of Science, Bangalore are described. Important research work undertaken in this tunnel over the last two decades is reviewed. Major aerodynamic data generated in this facility include measurement of aerodynamic force coefficients over missile shaped bodies, heat transfer rate measurements for space vehicle models such as SLV-3 and PSLV at various Mach numbers, and also generation of heat transfer data over flat plates to be used for validation of CFD codes. 


\section{References}

Anderson J D Jr 1989 Hypersonic and high temperature gas dynamics (New York: McGraw-Hill) Baskaran V 1977 Heat transfer measurements over a flat plate in a shock tunnel at $M=4$. M E dissertation, Department of Aerospace Engineering, Indian Institute of Science, Bangalore

Bernstein L, Stott G T 1981 A laser interferometric trajectory-following system for determining forces on freely flying models in a shock-tunnel. Proc. 13th Int. Symp. on Shock Tubes and Waves (eds) C E Treanor, J G Hall (New York: State University Press) pp 150-158

Channa Raju 1989 Aerodynamic force measurements over missile shaped bodies. ME dissertation, Department of Aerospace Engineering, Indian Institute of Science, Bangalore

Channa Raju, Reddy N M 1990 Aerodynamic force measurements over missile configurations in IISc shock tunnel at $\mathrm{M}_{\infty}=3.85$ and 9.15. Exp. Fluids 10: 175-177

Fay J A, Riddell F R 1958 Theory of stagnation point heat transfer in dissociated air. J. Aero.Sci. 25: 73-85

Hopkins E J 1972 Charts for predicting turbulent skin friction from Van Driest II. NASA TN-D 6945

Hornung H G 1988 28th Lanchester Memorial Lecture-Experimental real-gas hypersonics. Aero. J. Dec 379-389

Jagadeesh G, Srinivasa Rao B R, Nagashetty K, Reddy N M, Reddy K P J 1996 A new technique for visualization of shock shapes in hypersonic shock tunnel. Curr. Sci. 71: 128-130

Joshi M V 1985 Aerodynamic force measurements over missile configurations in IISc shock tunnel at $M_{\propto}=5.5$. M E dissertation, Department of Aerospace Engineering, Indian Institute of Science, Bangalore

Joshi M V, Reddy N M 1985 Aerodynamic force measurements over missile configurations in IISc shock tunnel at $\mathrm{M}_{\infty}=5.5$. Presented at National Conference on Aerodynamics, Indian Institute of Technology, Madras

Joshi M V, Reddy N M 1986 Aerodynamic force measurements over missile configurations in IISc shock tunnel at $M_{\infty}=5.5$. Exp. Fluids $4: 338-340$

Korkegi R H 1962 Hypersonic aerodynamics. Course Note 9, Training Centre for Experimental Aerodynamics, Belgium

Reddy K P J, Keshavamurthy K S, Reddy N M 1993 Design calculations of the proposed IISc free piston driven shock tunnel. Report 93 HEA1, Department of Aerospace Engineering, Indian Institute of Science, Bangalore

Reddy K P J, Keshavamurthy K S, Reddy N M 1994 Design calculations of the proposed IISc free piston driven shock tunnel: Detailed results. Report 94 HEA1, Department of Aerospace Engineering, Indian Institute of Science, Bangalore

Reddy N M 1978 Development of a hypersonic shock tunnel. Proc. Indian Acad. Sci. C1: 73-92

Reddy N M 1983 Aerodynamic force measurements in the IISc hypersonic shock tunnel. Proc. 14th Int. Shock Tube Symp. (eds) R D Archer, B E Milton, pp 358-362

Reddy N M, Reddy K P J 1988 Fast response data acquisition system for hypersonic shock tunnel measurements. Presented at 1st Natl. Symp. on High Speed Instrumentation, Terminal Ballistics Research Laboratory, Chandigarh

Reddy N M, Srinivasa P 1990 Analysis of heat transfer distributions over bulbous heat shield of launch vehicle at hypersonic speeds. J. Energy, Heat Mass Transfer 12: 77-81

Reddy N M, Viswanath P R 1977 SLV-3 nose cone heat flux measurements in the IISc shock tunnel. Report 77 FM 10, Department of Aerospace Engineering, Indian Institute of Science, Bangalore

Reddy N M, Srinivasa P, Reddy K P J, Raveendran P G 1988 Heat transfer measurements in 
shock tunnel on axisymmetric bodies at large incidence. Report No. STC-88-J01, Department of Aerospace Engineering, Indian Institute of Science, Bangalore

Remesh N 1996 Measurement of heat transfer and skin friction over a flat plate at $M_{\alpha}=5.75$ in IISc shock tunnel. M E dissertation, Department of Aerospace Engineering, Indian Institute of Science, Bangalore

Shah K K 1983 Aerodynamic force measurements over a blunt cone at $M_{\propto}=6 . \mathrm{M} \mathrm{E}$ dissertation, Department of Aerospace Engineering, Indian Institute of Science, Bangalore

Sreekanth 1993 Transpiration cooling analysis at hypersonic Mach numbers using N-S equations. Ph D dissertation, Department of Aerospace Engineering, Indian Institute of Science, Bangalore

Srinivasa P 1991 Experimental investigation of hypersonic flow over a bulbous heat shield at Mach number 6. Ph D dissertation, Department of Aerospace Engineering, Indian Institute of Science, Bangalore

Swaminathan S 1983 Three-dimensional nonequilibrium viscous shock layer flows over reentry vehicles. Ph D dissertation, Virginia Polytechnic Institute and State University, Blacksburg, VA

Tobak M, Peake D J 1979 Topology of two-dimensional and three-dimensional separated flows. AIAA Paper-79-1480

Truitt R W 1959 Hypersonic aerodynamics (New York: Roland) 